\title{
Documentación gráfica de edificios históricos: principios, aplicaciones y perspectivas
}

\section{Graphic documentation of historical buildings: principles, applications and prospects}

\author{
Rafael Martín Talaverano \\ Universidad Politécnica de Madrid \\ e-mail: r.martin@upm.es
}

\section{RESUMEN}

La documentación gráfica de edificios históricos constituye una de las herramientas más potentes para la preservación de sus valores culturales materiales y es la base para su investigación, conservación y difusión. Si bien históricamente el dibujo manual ha sido la principal técnica de representación, recientemente se han desarrollado otras para mejorar la toma de datos y su posterior gestión. Este artículo tiene como objetivo mostrar de un modo claro y sencillo los principales conceptos vinculados a la elaboración de la documentación gráfica, para facilitar la selección de las técnicas de un modo razonable y eficaz. Para ello se exponen y comparan los distintos métodos actuales, ofreciendo además varios casos de estudio con los criterios considerados en cada uno de ellos. Como conclusión se describen las ideas fundamentales derivadas de este análisis, así como las perspectivas de futuro que a nuestro juicio abren vías de desarrollo en este campo.

Palabras clave: Patrimonio cultural, arquitectura, geometría, dibujo, levantamiento, topografía, fotogrametría, láser escáner, nube de puntos, modelo 3D, planimetría.

\begin{abstract}
The graphic survey of historical buildings is one of the most powerful tools to preserve its material cultural values and it is besides the basis for its research, conservation and dissemination. Although manual drawing has been historically the main representation technique, some other methods have been recently developed to improve the data capture and its later management. This article aims to show clearly the basic concepts related to the making process of the graphic documentation in order to make possible to select reasonably and effectively such techniques. For this purpose, a comparative analysis of the current methods is firstly shown, followed by several case studies and those criteria taken into consideration within them. Finally, the main ideas obtained in the previous analysis are presented, as well as the future prospect that in our opinion set new development ways in this field.
\end{abstract}

Keywords: Cultural heritage, architecture, geometry, drawing, survey, topography, photogrammetry, laser scanner, point cloud, 3D model, planimetry.

Recibido: 12 mayo 2014. Aceptado: 9 septiembre 2014.

Cómo citar este artículo / Citation

Martín Talaverano, R.: "Documentación gráfica de edificios históricos: principios, aplicaciones y perspectivas", Arqueología de la Arquitectura, 11: e011, doi.org/10.3989/arq.arqt.2014.014

\section{Copyright}

(c) 2014 CSIC. Este es un artículo de acceso abierto distribuido bajo los términos de la licencia Creative Commons Attribution-Non Commercial (by-nc) Spain 3.0. 


\section{1.- INTRODUCCIÓN}

El patrimonio histórico edificado engloba una serie de valores culturales materiales, entre los que se pueden destacar los arquitectónicos (relativos a la forma, el espacio y la tecnología constructiva), los arqueológicos (entendiendo el edificio como un conjunto de tipos constructivos con su secuencia estratigráfica y sus relaciones contextuales) o los artísticos (relacionados con el estilo). Todos ellos son valores que han de ser debidamente registrados para ser preservados, lo cual se consigue con una adecuada documentación gráfica. Al margen de esta consideración, los trabajos de representación de edificios históricos han ido tradicionalmente vinculados a la labor restauradora de los mismos. Sin pretender profundizar en la historia de la restauración (ver Capitel 1998; Ceschi 1970; González-Varas 1999; Jokiletho 1999; Lamberini 2003 o Martínez 2000), sí es conveniente puntualizar la estrecha relación entre las distintas corrientes restauradoras y las diversas formas de elaborar la correspondiente documentación gráfica.

Atendiendo a la experiencia española, podemos señalar que no ha sido hasta tiempos recientes en que se ha empezado a tomar conciencia de la necesidad de elaborar una adecuada y rigurosa documentación gráfica de los edificios como base para su conocimiento e intervención. Ha sido usual hasta hace pocos años (y lo sigue siendo en algunos casos) manejar planimetrías idealizadas o simplificadas en exceso, que no reflejan la realidad compleja del edificio histórico ni sus valores culturales materiales. Además, se ha considerado en ocasiones la representación gráfica como un elemento de exhibición del virtuosismo de sus creadores, sin atender a su finalidad esencial como documento de un bien cultural. Por otro lado, el desarrollo de nuevas técnicas para la toma de datos ha ampliado el espectro de posibilidades y métodos, siendo compleja en algunos casos la elección por parte del usuario final, que queda a expensas de la opinión interesada de los proveedores de dichas tecnologías.

El presente texto surge a partir de las necesidades y carencias identificadas a lo largo de nuestra experiencia profesional en este campo. Por ello, creemos importante reivindicar una vez más la importancia de una adecuada documentación gráfica del patrimonio edificado, algo que, si bien es ya una idea recurrente a nivel teórico, no percibimos que esté asumida de un modo generalizado en la práctica. Por otro lado, ante la extensa gama de técnicas y métodos para abordar la documentación gráfica, este artículo pretende aportar una visión comparativa de los mismos de cara a obtener criterios claros y razonables para la elección por parte de los usuarios potenciales. Debemos dejar claro que no es este un texto que profundiza en las descripciones técnicas (ya existen publicaciones al respecto, como Docci y Maestri 1994; Jiménez y Pinto 2003 o Almagro 2004), sino que pretende ofrecer ideas y criterios relativamente sencillos, basados en nuestra experiencia como usuarios de dichas tecnologías.

\section{2.- REPRESENTACIÓN GRÁFICA DE EDIFICIOS HISTÓRICOS}

\section{1.- La representación como interpretación de la realidad material}

A lo largo de la historia, la representación gráfica de los elementos arquitectónicos ha sido una de las herramientas fundamentales tanto para la concepción y ejecución material de un proyecto, como para la documentación o difusión (con distintos fines) de los edificios ya construidos. El método por excelencia de representación ha sido y sigue siendo el dibujo de arquitectura, caracterizado por la definición de las propiedades geométricas y constructivas de los edificios a través de planos de planta, alzados y secciones, así como perspectivas cónicas o axonométricas (Sainz 2005). Recientemente han aparecido otros medios complementarios, como la fotografía, el vídeo o las modelizaciones informáticas tridimensionales. No obstante, en adelante nos centraremos en el dibujo de arquitectura, entendido en su vertiente bidimensional (planimetrías), así como en los modelos tridimensionales.

Cualquier proceso de representación de un edificio debe ir precedido de un conocimiento del mismo, puesto que el dibujo de arquitectura se basa en una interpretación de la realidad construida, es decir, en el análisis de los datos obtenidos para poder extraer los aspectos fundamentales que se deseen plasmar en la documentación gráfica (Figura 1). El elemento básico del dibujo, la línea, no deja de ser una abstracción del límite entre el lleno o el vacío, o el contorno aparente de los volúmenes que configuran la materialidad construida. La decisión sobre el trazado de dichas líneas precisa de un conocimiento del edificio y su configuración constructiva y además implica una selección de la información para representar los elementos. Por ello, en todo momento existe una intencionalidad en la representación, de modo que es un proceso subjetivo y, por lo tanto, imposible de automatizar completamente (Ortega, Martínez y Muñoz 2011: 55). 


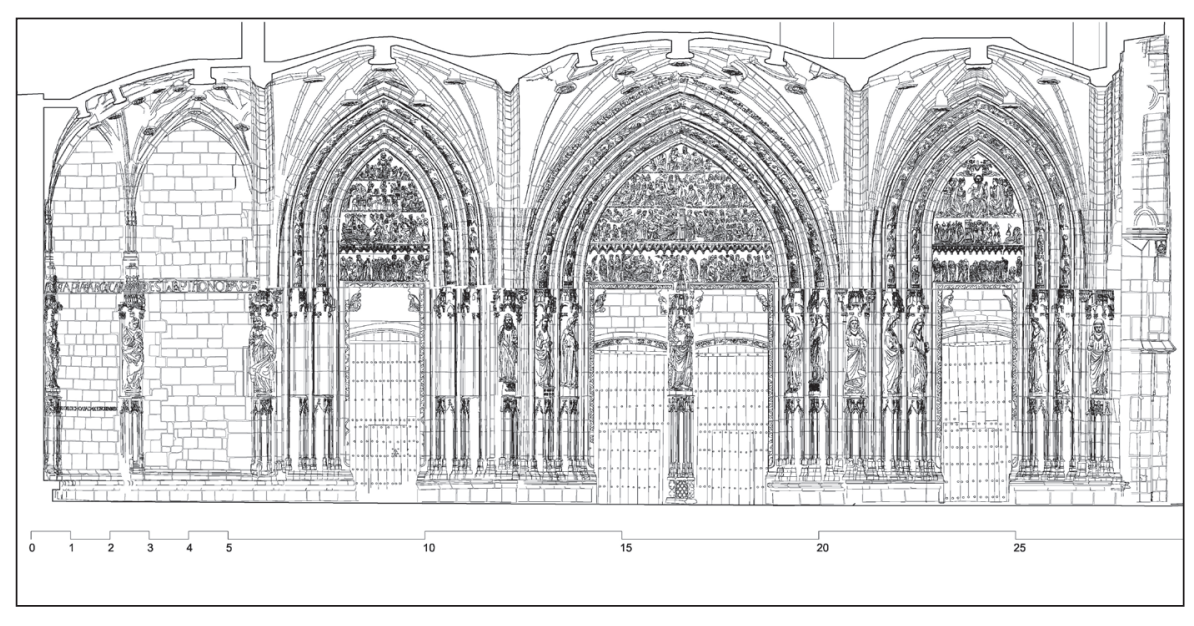

Figura 1. Sección del pórtico de la catedral de Santa María (Vitoria-Gasteiz). Fundación Catedral Santa María. Realización, Latorre y Cámara S.L.
Por otro lado, el proceso de representación gráfica, al implicar un análisis geométrico y constructivo, se convierte en un auténtico proceso de investigación. De este modo, cualquier elaboración de la planimetría de un edificio histórico debería suponer un avance en el conocimiento y la difusión del mismo (Ortega, Martínez y Muñoz 2011: 57). El papel de las tecnologías aplicadas a la restitución gráfica (láser escáner, fotogrametría, termografías, georradar, fotografía espectroscópica, etc.) es muy notable, ya que han supuesto una multiplicación de las posibilidades de la toma y gestión de los datos y han permitido que el registro gráfico final sea más riguroso y preciso. Sin embargo, dichas herramientas tecnológicas no deben ser un fin en sí mismas, sino servir a los objetivos de la documentación gráfica.

\section{2.- Finalidad y alcance de la documentación gráfica}

La representación gráfica del patrimonio cultural edificado debe ser ante todo una vía para registrar y documentar sus valores culturales materiales, asegurando su preservación. Aunque en ocasiones esta premisa fundamental se deja de lado, creemos que una adecuada documentación gráfica puede ser uno de los más efectivos medios para la conservación del patrimonio cultural, gracias a los relativamente reducidos recursos que se necesitan y la elevada cantidad de información registrada y salvaguardada. En un caso extremo, un edificio podría desaparecer, quedando sus valores culturales materiales convenientemente preservados mediante una completa documentación gráfica.

Cabe además destacar los valores arqueológicos que el patrimonio cultural edificado posee, configurados mediante las relaciones estratigráficas y tipológicas entre los materiales. Estas relaciones, así como la secuencia que se genera, son las que proporcionan la información necesaria para entender la evolución constructiva del edificio y su contextualización espacial, temporal y social. La riqueza de relaciones es la base de la evocación del paso del tiempo a través del mismo y, en gran medida, de la noción de antigüedad que desprende (Caballero y Latorre 1995: 10-11). Por ello, el adecuado registro de dichas relaciones, así como la correcta definición de los materiales y sistemas constructivos del edificio histórico, se convierten en requisitos básicos de la documentación gráfica, ya que supone la salvaguarda de buena parte de sus valores culturales materiales (Figura 2).

Además del registro de dichos valores, se deben atender las necesidades particulares de los trabajos posteriores (investigación, conservación y/o difusión) que tendrán como base fundamental la documentación gráfica. En primer lugar, la documentación gráfica sirve como herramienta básica para la investigación y conocimiento de los edificios históricos. Así, puede emplearse para el análisis arquitectónico (tipología edificatoria, diseño y trazado, usos y funciones, materiales y técnicas constructivas, sistemas estructurales, contexto urbano, etc.), para la investigación arqueológica (tanto en excavaciones como en el análisis de los paramentos, con todos sus materiales y sistemas constructivos) o en los estudios artísticos (elementos tipológicos singulares como capiteles, basas, molduras, esculturas, etc.). Incluso otros campos tradicionalmente más alejados del ámbito del patrimonio cultural, como la ingeniería civil, se apoyan en la documentación gráfica de obras como presas, puentes, molinos, etc. En cualquier caso, cada tipo de estudio posee unas necesidades específicas que la documentación gráfica ha de atender.

Más allá de la investigación, la planimetría rigurosa y completa de un edificio histórico es la base sobre la que desarrollar cualquier proyecto de intervención. 


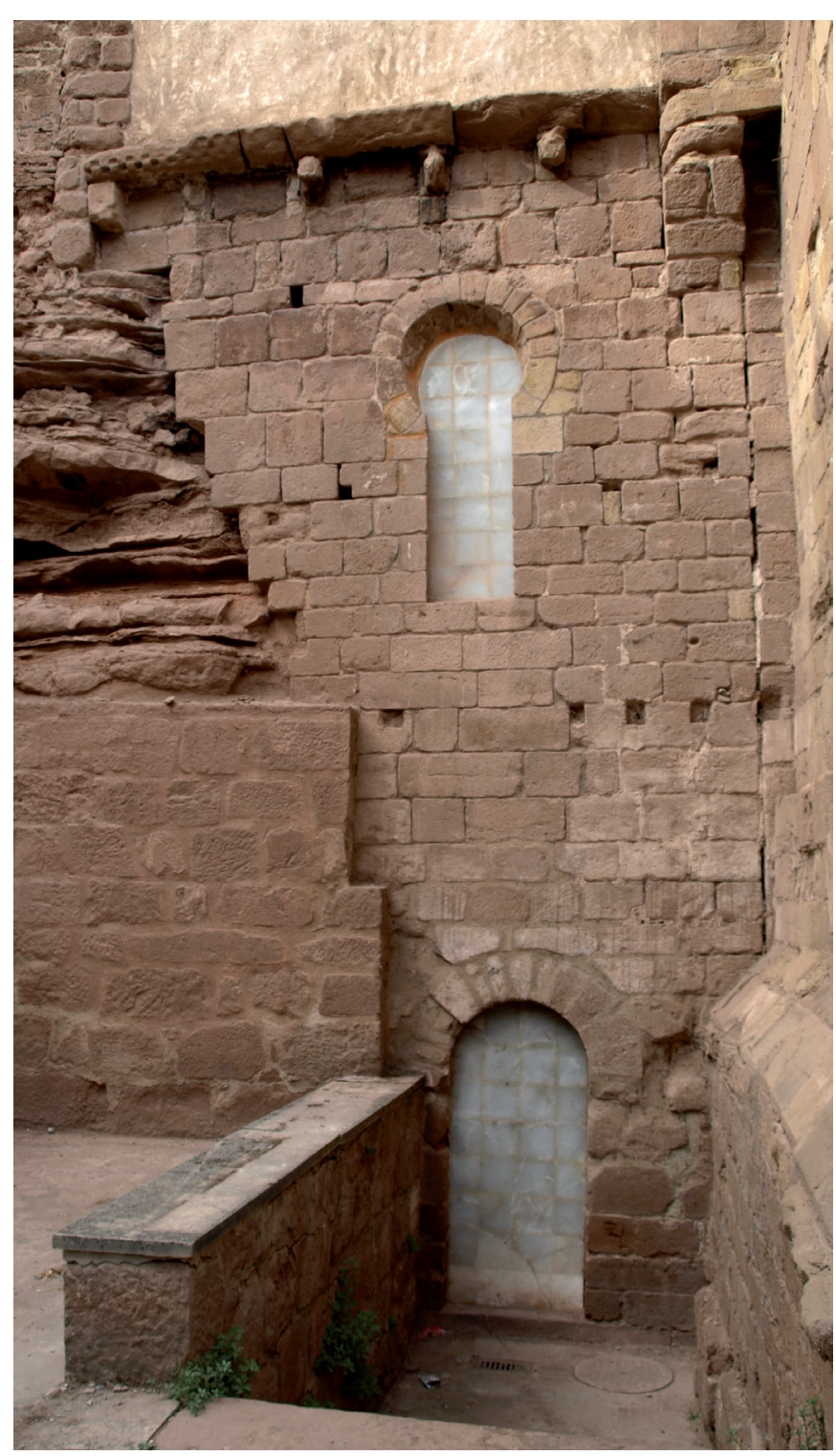

Figura 2. Muro de la iglesia del monasterio de Santa María la Real (Nájera).

A los estudios previos, constituidos por los análisis anteriormente mencionados, se le añaden los estudios de lesiones que generalmente demandan tanto información de color mediante imágenes (para registrar grietas, alteraciones superficiales, coloraciones, elementos vegetales, suciedad, etc.), como datos de la geometría tridimensional real (para analizar deformaciones, movimientos, roturas, giros, etc.) que permiten analizar el comportamiento estructural. Todos estos trabajos tienen como soporte la documentación gráfica (bidimensional y tridimensional), que se constituye en una base común fundamental para desarrollar un diagnóstico patológico integrado y eficaz, ya que sobre ella pueden represen- tarse, compararse y analizarse los distintos resultados. Posteriormente, la intervención, como cualquier otro proyecto de arquitectura, se basa esencialmente en la planimetría, tanto para concebirse como para generar los documentos técnicos que hagan posible su realización.

Sin embargo, las aplicaciones de la documentación gráfica no se limitan a la investigación y la conservación del patrimonio construido. También constituye una base fundamental para la difusión de sus valores culturales. En este sentido, la documentación gráfica de un edificio histórico es por sí misma una base para la transmisión de los mismos (con el adecuado tratamiento de la información). Pero además, a partir de los modelos tridimensionales es posible obtener recreaciones virtuales (estáticas o animadas) del objeto, constituyendo una herramienta de gran ayuda para la musealización, ya que permiten entender y disfrutar en mayor medida el patrimonio cultural por parte del público no especializado.

\section{3.- MÉTODOS PARA LA DOCUMENTACIÓN GRÁFICA}

\section{1.- Conceptos generales}

Antes de pasar a la descripción sintética de los distintos métodos, conviene aclarar algunos aspectos clave que pueden generar confusión, como las diferencias existentes entre una imagen de mapa de bits (imagen raster) y un dibujo o imagen vectorial. Si bien ambos son documentos gráficos, la imagen de mapa de bits se compone de un conjunto de «pixeles» o puntos homogéneamente distribuidos que contienen información de color, pero no ofrecen directamente ningún tipo de interpretación geométrica o constructiva. La cantidad de información queda determinada entonces por la densidad de «pixeles» en el conjunto de la imagen. Dicho parámetro nos permite acercarnos en menor o mayor medida al objeto representado sin perder la cualidad continua de la imagen, limitada en el momento en que dicha imagen se «pixeliza», o lo que es lo mismo, se hacen visibles los «pixeles» (Figura 3).

Frente a este documento de información continua e indiscriminada, el dibujo de arquitectura proporciona una interpretación discriminada y selectiva de la realidad construida, basada en puntos y líneas. Esta información gráfica describe la geometría, los materiales y los sistemas constructivos del edificio a partir de unos datos determinados, desechando otros. Por ello, cada uno de los documentos (imagen de mapa de bits y dibujo o imagen vectorial) aporta una información distinta, en muchas ocasiones complementaria, pero no intercambiable. 

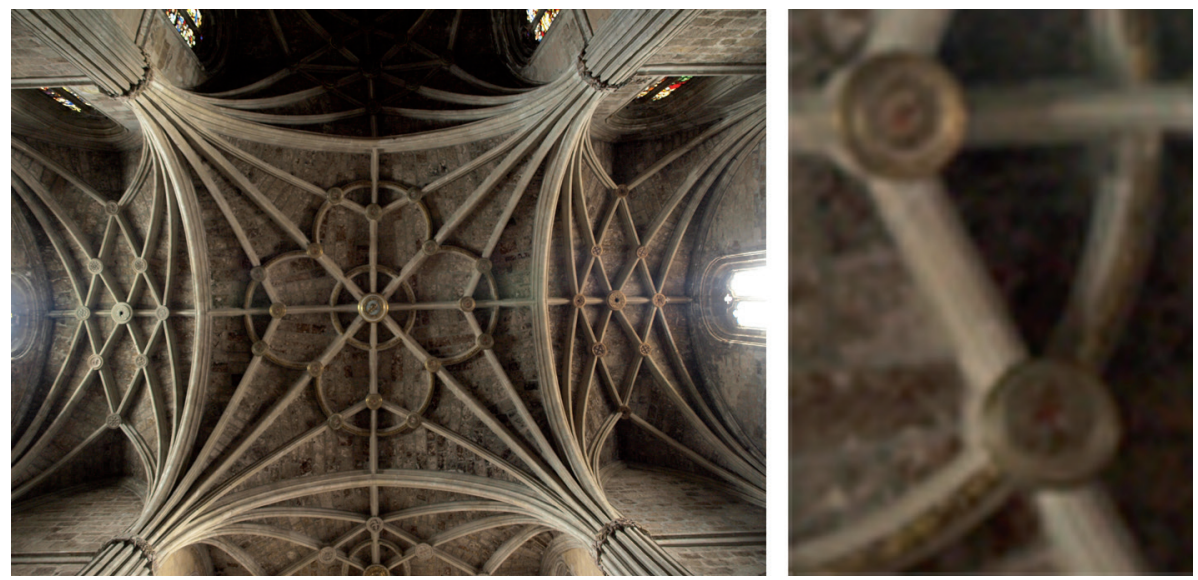

Figura 3. Imagen de mapa de bits y ampliación de la misma con «pixelización». Bóveda de la iglesia del convento de San Marcos (León).
En ambos, es necesario distinguir el concepto de precisión frente al de detalle. El primero de ellos hace referencia a la exactitud geométrica de la información respecto a la realidad de un determinado método, o lo que es lo mismo, qué margen de error métrico estamos asumiendo al emplearlo $(1 \mathrm{~m}, 1 \mathrm{~cm}, 1 \mathrm{~mm} . .$.$) . Por ello,$ es fundamental tener claro el grado de error asumible, en función de los propósitos de la documentación gráfica y de las características del objeto a documentar, de tal modo que no aporta ninguna ventaja disponer de registros de medidas más pequeñas que las propias irregularidades que pueda tener el edificio.

Frente a la noción de precisión, el grado de detalle se refiere a la cantidad de información que proporciona el documento gráfico, independientemente de su rigor métrico. De este modo, un dibujo puede contener un elevado nivel de detalle (representando hasta los más pequeños matices de un motivo ornamental), pero carecer de una adecuada precisión métrica. Por el contrario, un documento gráfico puede contener el mínimo nivel de información pero estar muy ajustado métricamente a la realidad. Una vez más, el adecuado equilibrio entre precisión y detalle es una de las claves para obtener una documentación gráfica eficaz.

Una vez revisados estos conceptos generales, pasaremos a continuación a describir brevemente las distintas técnicas de levantamiento agrupadas en tres categorías principales: manual, instrumental y fotogrametría.

\section{2.- Levantamiento manual}

La toma de datos manual ha sido el método tradicional para la realización de levantamientos arquitectónicos, consistente en mediciones lineales (cinta métrica), así como sistemas de control de la verticalidad y los niveles (plomada y nivel de agua), que se registran en los correspondientes croquis de campo. La realización de croquis a mano alzada constituye un proceso de pensamiento y un paso fundamental en la interpretación constructiva del

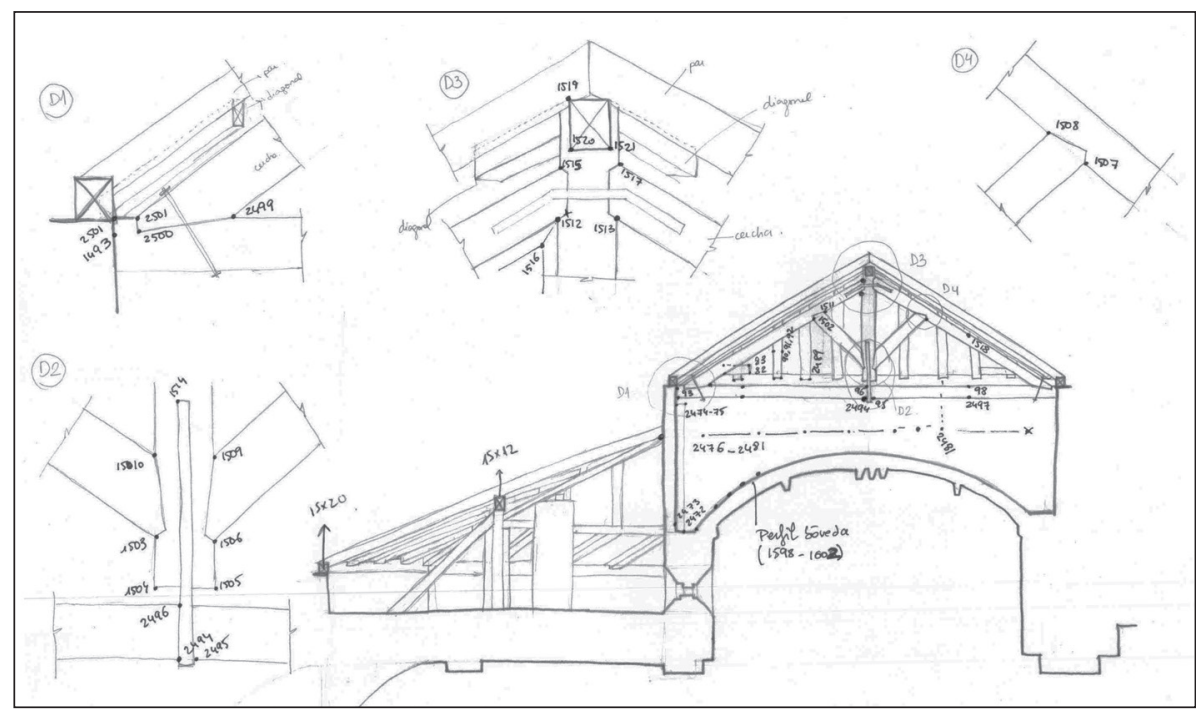

Figura 4. Croquis de campo de la iglesia de Nuestra Señora de Campanario (Almazán). Realización, Carmen Pérez de los Ríos. 
edificio, de modo que mientras se dibuja in situ se está llevando a cabo una investigación sobre sus características materiales (Figura 4). La oportunidad de observar cada uno de los elementos desde distintos ángulos y distancias (incluso acercándose hasta tocarlo) no se puede sustituir por el trabajo de gabinete a base de imágenes.

Por otro lado, el dibujo y la medición de detalles (como carpinterías, molduras, elementos decorativos, etc.) sólo pueden hacerse in situ si se quieren obtener unos resultados satisfactorios. Además, la medición manual permite acceder a algunos lugares recónditos de un edificio (bajocubiertas, escaleras de caracol, etc.), donde es complicado desarrollar el levantamiento con otras técnicas. Por el contrario, en muchas ocasiones este tipo de toma de datos es totalmente inviable, debido a la imposibilidad de acceso directo al objeto medido.

Sin embargo, para conseguir la interrelación de los distintos datos métricos es necesario desarrollar una sistemática triangulación que los incluya en un sistema general de referencia. Por ello, en el contexto general del levantamiento de un edificio completo, la medición manual de plantas, alzados y secciones adolece de una falta de precisión considerable. Además, la gestión de los datos obtenidos es compleja y sujeta a errores, debido a su escaso grado de informatización. Por ello entendemos que las mediciones y croquis manuales son esenciales en cualquier levantamiento, pero como complemento de otros sistemas.

\section{3.- Levantamiento instrumental}

\section{Conceptos generales}

Frente a la toma de datos manual, existen actualmente una serie de instrumentos que aportan una mayor rapidez $\mathrm{y}$ facilidad en el proceso de toma de datos, ya que, sobre todo, permiten la medición a distancia de puntos inaccesibles. Además, los dispositivos permiten la medición a distancia con láser de puntos sobre elementos inaccesibles y en general posibilitan una gestión informatizada de los datos, los cuales se registran automáticamente en archivos de coordenadas y pueden ser fácilmente manejados en aplicaciones CAD.

El más básico de los instrumentos es el distanciómetro láser, un pequeño aparato de mano que permite obtener mediciones de distancias de forma rápida, gracias al empleo de un rayo láser que rebota sobre la superficie medida. Sin embargo, los datos obtenidos no están relacionados entre sí con un sistema de referencia común, por lo que su aplicación es, al igual que la cinta métrica, complementaria a otros sistemas. Un instrumento de aplicación también limitada es el teodolito, que permite medir ángulos horizontales y verticales respecto de una orientación de referencia dada. De este modo, midiendo los ángulos de los rayos visuales lanzados a un mismo punto desde dos posiciones distintas $\mathrm{y}$ conocidas, se puede calcular su posición relativa a dichas posiciones.

La combinación de la medición de ángulos con la obtención de distancias mediante el empleo de un rayo láser, todos ellos integrados en un único sistema de referencia, es la base de una serie de dispositivos más sofisticados que nos permiten abordar con garantías de rigor métrico el levantamiento de un edificio completo, como la estación total o el escáner láser. Estos aparatos permiten la medición de puntos referenciados a un sistema de coordenadas común, que debe ser definido inicialmente, configurándose así la estación o punto base desde la cual se radian los puntos sobre el edificio. En principio, dicha medición se basa en un sistema de coordenadas polares, registrándose el ángulo horizontal (respecto de una dirección horizontal establecida como origen), el ángulo vertical (respecto del plano horizontal) y la distancia desde la estación al punto medido; así se configura lo que se denomina «lectura» de cada punto. El conjunto de lecturas (ángulo horizontal, ángulo vertical y distancia) son automáticamente convertidas en coordenadas cartesianas $(\mathrm{x}, \mathrm{y}, \mathrm{z})$, referidas al sistema definido inicialmente.

De este modo, se obtiene el conjunto de puntos radiados desde una estación. Sin embargo, dadas las características geométricas de los edificios, no suele ser suficiente con la medición desde una única estación, ya que generalmente no se visualizan todos los puntos desde una ubicación. Por ello es preciso repetir el proceso desde distintas estaciones, las cuales deben quedar convenientemente referenciadas entre sí, generándose un itinerario preferentemente cerrado. Así, se asegura que todas las mediciones están referidas a un mismo sistema de coordenadas, generándose un conjunto de puntos coherente.

A partir de estos principios básicos, existe una amplia gama de dispositivos topográficos que ofrecen distintas prestaciones. Sin pretender desarrollar una descripción exhaustiva en el presente texto, sí creemos conveniente apuntar algunos tipos básicos para orientar en la elección por parte de los usuarios, los cuales encontrarán más información en las correspondientes casas comerciales. 


\section{Estación total}

En primer lugar, encontramos las estaciones totales, las cuales, en su versión más básica, se limitan a la medición punto a punto tal y como se ha descrito anteriormente. Es este un proceso con el nivel más bajo de automatización, ya que el usuario debe seleccionar cada punto y medirlo independientemente. La medición de los puntos es por lo tanto totalmente discriminada y selectiva, puesto que sólo se miden los puntos deseados; por ejemplo aquellos que definen la geometría general de los distintos elementos del edificio, como muros, huecos, cubiertas, bóvedas, etc. (Figura 5). Al ser un método selectivo, requiere más tiempo en campo que el resto de métodos automatizados, aunque ello permite por otro lado alcanzar una comprensión más profunda del edificio y sus elementos.

A partir del modelo básico de estación total, se han desarrollado otros tipos, como la estación total robotizada o la estación de imagen. La primera permite definir un margen espacial dentro del cual el dispositivo realiza una medición automática de todos los puntos con una distancia entre ellos especificada previamente.

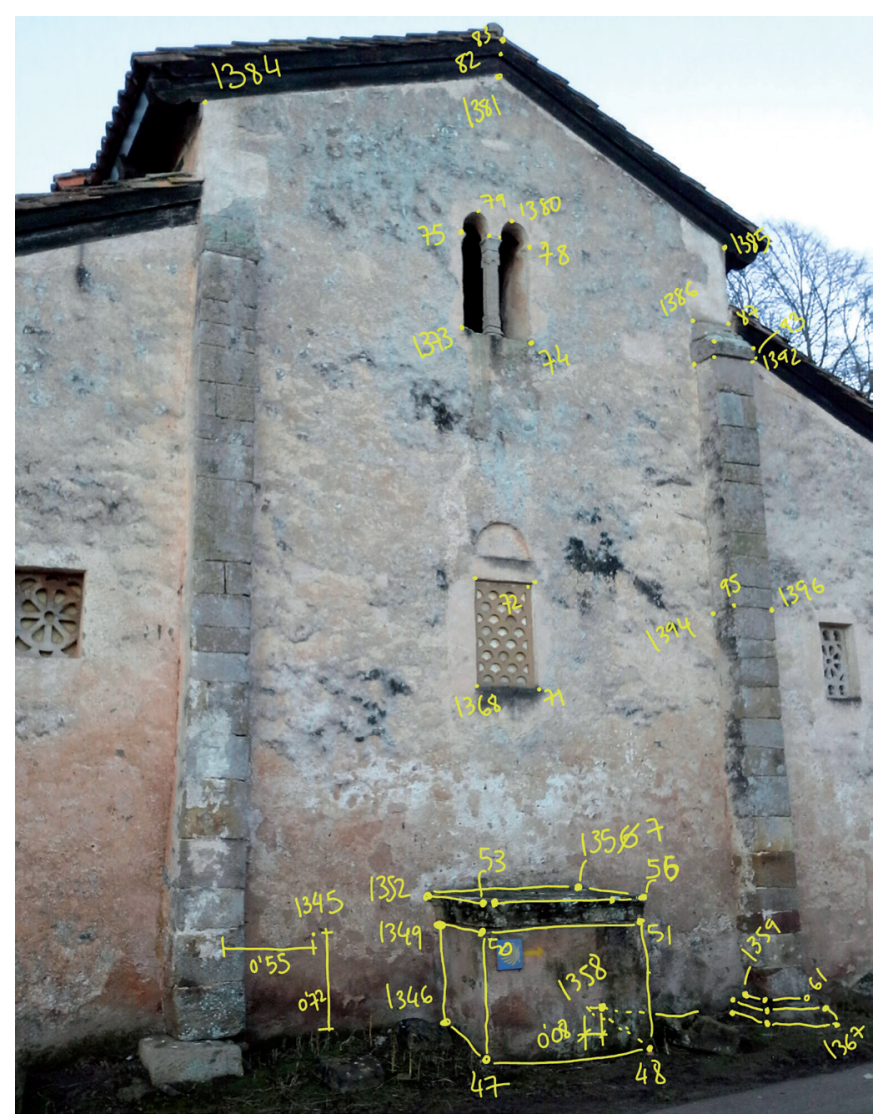

Figura 5. Croquis de campo con puntos medidos en la iglesia de San Salvador (Priesca).
Sin llegar a las prestaciones de un escáner láser, permite acelerar notablemente el proceso, a costa de realizar una medición indiscriminada. El segundo tipo de estación incorpora una cámara fotográfica que aporta la información de color de cada uno de los puntos medidos, la cual puede ser útil en función de los casos. Además, continuamente se desarrollan mejoras tecnológicas que permiten la detección automática de prismas, la autonivelación de los dispositivos, etc.

\section{Escáner láser}

En los últimos años, el escáner láser terrestre ha venido a revolucionar el panorama actual de la cartografía de edificios. No pretendemos aquí desarrollar una descripción técnica de un dispositivo tan complejo, la cual puede además consultarse en otras publicaciones (Lichti, Pfeifer y Maas 2008; Mañana-Borrazas, Rodríguez y Blanco-Rotea 2008; García-Gómez, Fernández de Gorostiza y Mesanza 2011), pero sí creemos conveniente aportar ideas básicas sobre su funcionamiento y los resultados que se obtienen.

En primer lugar, cabe destacar que este dispositivo conlleva el más alto grado de automatización, lo que permite obtener en un tiempo muy corto una gran cantidad de información, pero por el contrario es un sistema totalmente indiscriminado (no se selecciona ningún punto, sino que se miden todos). Basado en un sistema motorizado, el escáner láser realiza un barrido de mediciones a una alta velocidad, combinando un movimiento horizontal con giros verticales que le permiten alcanzar todos aquellos puntos que no queden ocultos desde la posición del aparato. Las lecturas efectuadas son registradas automáticamente, de tal modo que el conjunto de puntos medidos configura lo que viene a llamarse «nube de puntos», dada su elevada densidad. Este dispositivo de registro permite elaborar una documentación gráfica de alta definición (High-Definition Survey, HDS). Además, algunos dispositivos incorporan cámaras fotográficas sincronizadas, por lo que junto a las coordenadas espaciales de cada punto se obtiene la cualidad del color de cada uno de ellos (Figura 6).

Para el adecuado empleo del escáner láser es importante controlar el tipo de láser, las distancias desde el aparato a los objetos que se quieren documentar y, sobre todo, la densidad de la captura. Es este último un parámetro fundamental, ya que define, en términos generales, la cantidad de puntos que se miden en cada unidad de desplazamiento del aparato. Por ello ha de ir relacionado con las necesidades de la documentación 


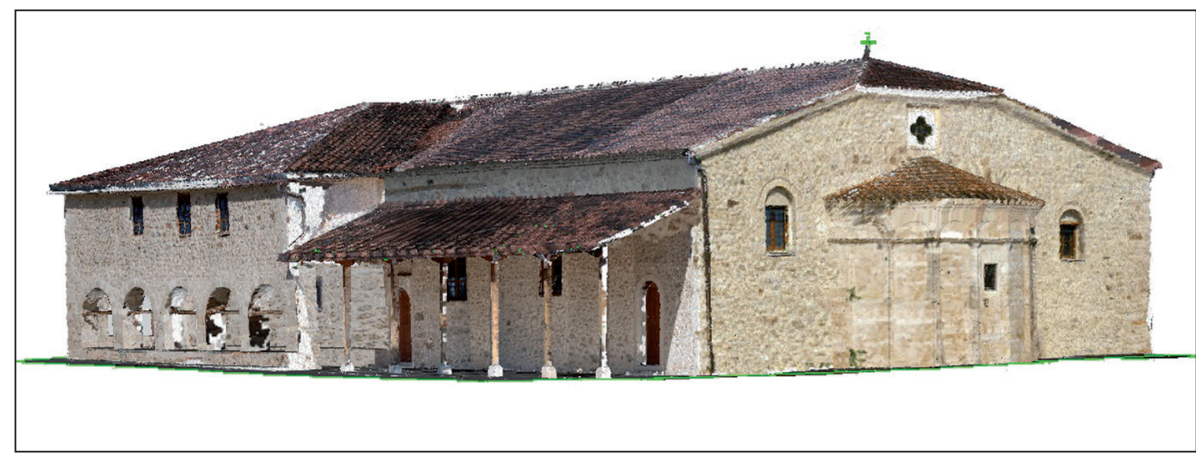

Figura 6. Nube de puntos obtenida con escáner láser en el monasterio de Panagia (Goumenissa, Grecia). Realización, Ioannakis Georgios-Alexis y Sidiropoulos Andreas (3D Documentation of cultural monuments using laser scanner - Case study: Monastery of Panagia, Goumenissa, Greece. School of Rural and Surveying Engineering of Aristotle University of Thessaloniki. Junio 2011).

gráfica que se va a elaborar y debe establecerse en función de las dimensiones y características geométricas de los elementos a representar.

\section{4.- Levantamiento mediante fotogrametría}

\section{Conceptos generales}

Frente a los métodos anteriores, basados en la medición directa de datos sobre el edificio, la fotogrametría se basa en el empleo de imágenes fotográficas de un objeto para obtener sus datos geométricos. Dado que la bibliografía al respecto es amplia (Almagro 2004; Álvarez, Lopetegui, Mesanza, Rodríguez, Valle y Vicente 2003; Antoñanzas, Iguácel, Lopetegui y Valle 2003; Cámara y Latorre 2003; e Iglesias 2002), en el marco del presente artículo, nos interesa únicamente apuntar las bases teóricas generales para entender los diversos métodos y sus aplicaciones. Aunque la técnica de la fotogrametría se desarrolló inicialmente con la fotografía analógica, nos referiremos a continuación a las aplicaciones que emplean fotografía digital, entendiendo que este formato es el más común actualmente.

La fotografía es un sistema de registro automático de imágenes perspectivas cónicas, similares a nuestra propia percepción visual, basadas en la intersección de un haz cónico de rayos proyectivos (que unen cada uno de los puntos del objeto con el centro de proyección, es decir, el observador) con el plano de proyección donde la imagen queda registrada (Figura 7). Al contrario que ocurre con las imágenes en perspectiva axonométrica, de las cuales sí se pueden obtener las dimensiones de los objetos directamente (puesto que es una proyección de rayos paralelos, no un haz cónico), con una única fotografía no es posible deducir la forma tridimensional de un edificio.

Sin embargo, a partir de dos imágenes fotográficas de un mismo objeto, conocidas su posición y orientación es posible calcular los rayos proyectivos de cada una correspondientes a un mismo punto de dicho objeto, obteniéndose su posición mediante la intersección de dichos rayos. Para realizar este proceso, es necesario conocer la posición del centro de proyección de cada una de las imágenes fotográficas (orientación interna) en relación con la posición y orientación de la cámara (orientación externa), reconstruyendo posteriormente el haz proyectivo y obteniéndose las direcciones de proyección de cada uno de los puntos. Así, podemos definir la fotogrametría como «aquella técnica que permite medir objetos, edificios o la misma superficie

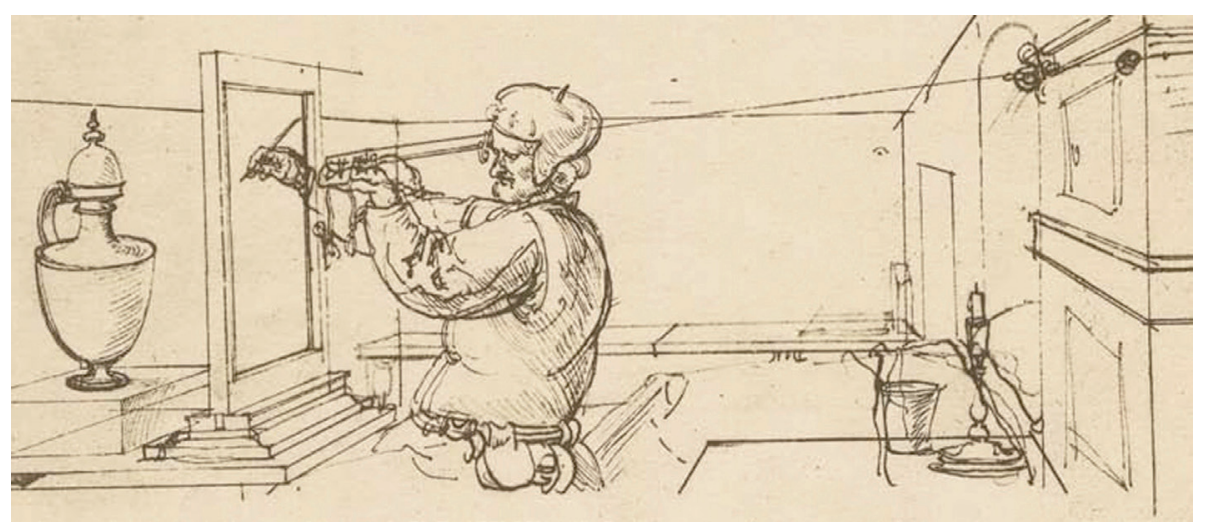

Figura 7. Dibujo de Albrecht Dürer (Skizzenbuch). 

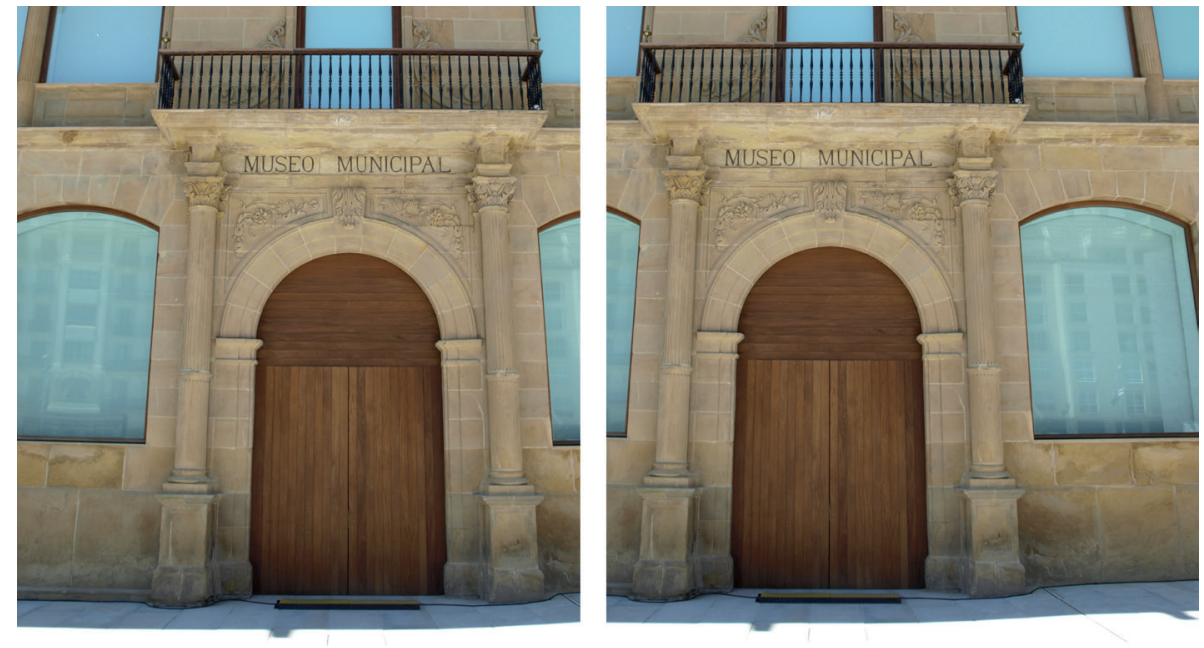

Figura 8. Par estereoscópico de la portada del convento de San Telmo (San Sebastián). terrestre a partir de imágenes perspectivas obtenidas por procedimientos fotográficos» (Almagro 2004: 52). No obstante, en el marco de esta definición es conveniente distinguir claramente dos técnicas cuya metodología y resultados son notablemente distintos, como son la fotogrametría tridimensional y la rectificación fotográfica (fotogrametría bidimensional). Queremos destacar este aspecto para no generar confusión con una terminología que engloba genéricamente a dos técnicas que a nuestro juicio son muy distintas.

\section{Fotogrametría tridimensional}

Como ya hemos apuntado anteriormente, en el proceso de obtención de la forma tridimensional de un objeto es necesario contar con al menos dos imágenes fotográficas del mismo, de modo que la restitución se desarrolla con varias imágenes, en contraste con la rectificación fotográfica que, como se verá más adelante, se basa en una única imagen fotográfica. También se ha señalado que la base de la restitución consiste en la determinación de la intersección de dos rayos proyectivos que unen el centro de proyección de cada toma (la posición de la cámara) con el punto a medir. Por ello, la mecánica de la restitución fotogramétrica se fundamenta en la identificación de dicho punto en cada fotografía, o, dicho de otro modo, la definición de los puntos homólogos que representan el mismo punto real en cada imagen.

Las distintas formas de identificar estos puntos homólogos han derivado en el establecimiento de dos técnicas fotogramétricas diferenciadas. La primera que se desarrolló es la denominada fotogrametría estereoscópica, basada en dos imágenes fotográficas (par estereoscópico), realizadas con la misma dirección y distancia al objeto, pero separadas lateralmente entre sí una pequeña distan- cia (Figura 8). A partir de dichos pares, gracias el empleo de estereoscopios o monitores estereoscópicos y gafas polarizadas es posible visualizar tridimensionalmente el objeto, de modo que con un puntero flotante es posible «recorrer» su superficie. El movimiento de dicho puntero a través del espacio tridimensional virtual es automáticamente traducido por una aplicación informática en los correspondientes pares de puntos homólogos de cada imagen fotográfica, calculando la posición espacial de los puntos del objeto real. De este modo, al mismo tiempo que se desplaza el puntero se pueden ir dibujando los distintos elementos en el espacio (aristas, juntas, revestimientos, etc.), obteniéndose modelos tridimensionales delineados, con la información seleccionada.

Por otro lado, han surgido recientemente aplicaciones informáticas capaces de automatizar en mayor o menor medida el proceso de identificación de puntos homólogos en varias imágenes fotográficas, acelerando notablemente la restitución de los objetos. Al no recurrirse a la visión estereoscópica, pueden emplearse más de dos fotografías, que además no tienen por qué tener direcciones paralelas entre sí, de ahí que se denomine a esta técnica como «fotogrametría convergente» o «multi-imagen» (Figura 9). Así, a partir de la identificación de una serie de puntos iniciales del objeto que aparezcan en todas ellas, mediante los correspondientes algoritmos y procesos de iteración, se puede obtener una nube de puntos tridimensional similar a la proporcionada por un escáner láser. Son diversas las aplicaciones informáticas que permiten desarrollar esta técnica, como Orthoware (www.orthoware.es), PhotoModeler Scanner (www.photomodeler.com) o PhotoScan (www.agisoft.ru/products/ photoscan). Incluso algunas aplicaciones, como $123 D$ 

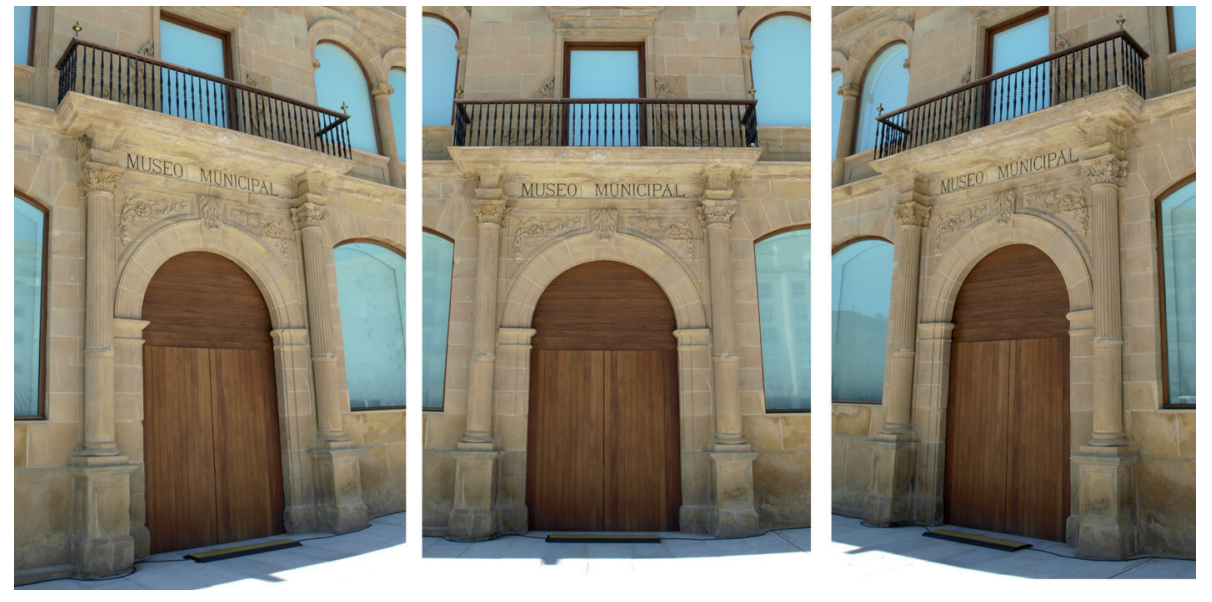

Figura 9. Fotografías convergentes de la portada del convento de San Telmo (San Sebastián).

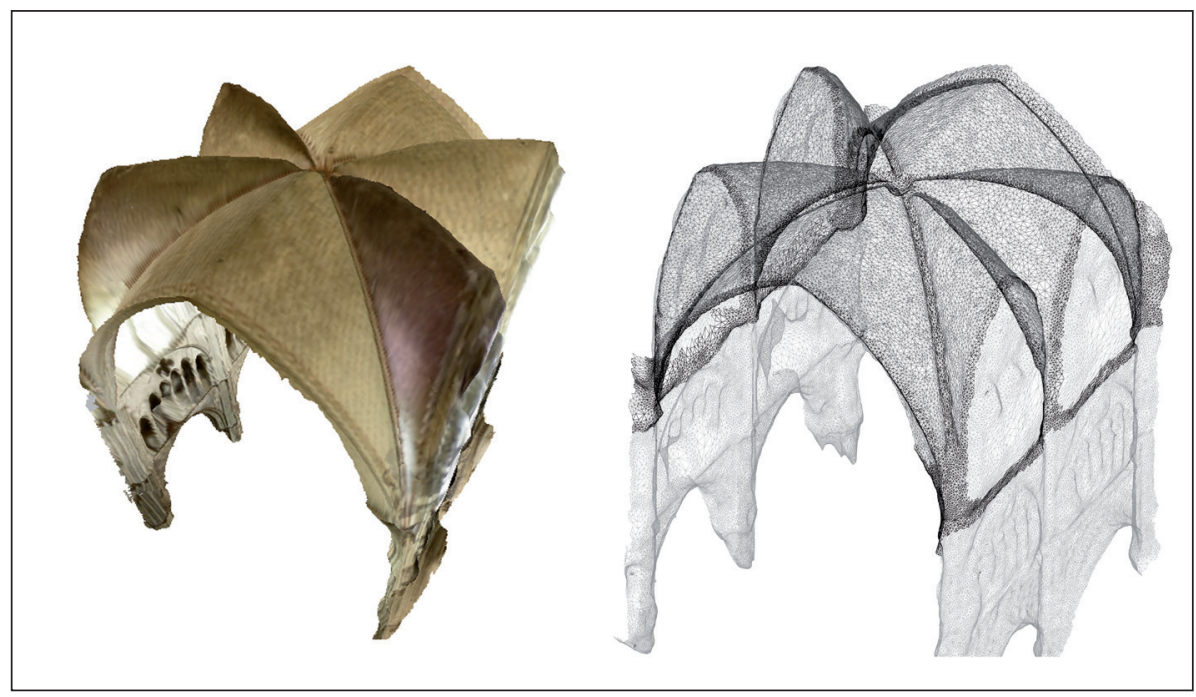

Figura 10. Levantamiento de las bóvedas sexpartitas de la Catedral de Bourges (Francia). Realizado con 123D Catch de Autodesk a partir de fotogrametría convergente o multi-imagen. A la izquierda modelo fotográfico, a la derecha malla triangulada. Realización, Rocío Maira Vidal. Enjarje Arquitectura (www.enjarje.com).

Catch (www.123dapp.com/catch) o $\operatorname{Arc3D}$ (www. arc3d.be), ofrecen la obtención de dichos resultados on-line, de modo que el usuario sólo tiene que enviar las fotografías y la aplicación le devuelve el modelo tridimensional (Figura 10).

\section{Rectificación fotográfica o fotogrametría bidimensional}

Tal y como se ha comentado anteriormente, la obtención de los datos geométricos tridimensionales de un objeto sólo es posible a partir de dos o más imágenes fotográficas. Sin embargo, con una única imagen es posible restituir elementos planos, sin información sobre su profundidad en la tercera dimensión. Es lo que se conoce como rectificación fotográfica, y tiene como objetivo conseguir una proyección ortogonal de un elemento plano del edificio, obteniéndose una representación bidimensional métricamente definida sobre la que se pueden realizar mediciones (ortoimagen).
Para ello sólo es necesaria una imagen fotográfica, así como una serie de medidas de apoyo que definen un perímetro en el interior del cual la imagen queda rectificada. Una vez más, encontramos varias aplicaciones informáticas con las que desarrollar esta técnica de un modo más o menos sencillo. Desde Photoshop, que permite deformar las imágenes en perspectiva (aunque con un nivel de error bastante alto), hasta aquellas aplicaciones específicas más completas como Homograf, ASRix (www.asrix.ca) o PhotoModeler Scanner (www.photomodeler.com), existe una amplia gama de productos para rectificar imágenes. En todos los casos, es preciso aportar puntos conocidos (medidos previamente con otra técnica) que definan el perímetro de rectificación, obteniéndose en el interior del mismo una ortoimagen frontal en verdadera magnitud como transformada de la imagen original en perspectiva (Figura 11). 

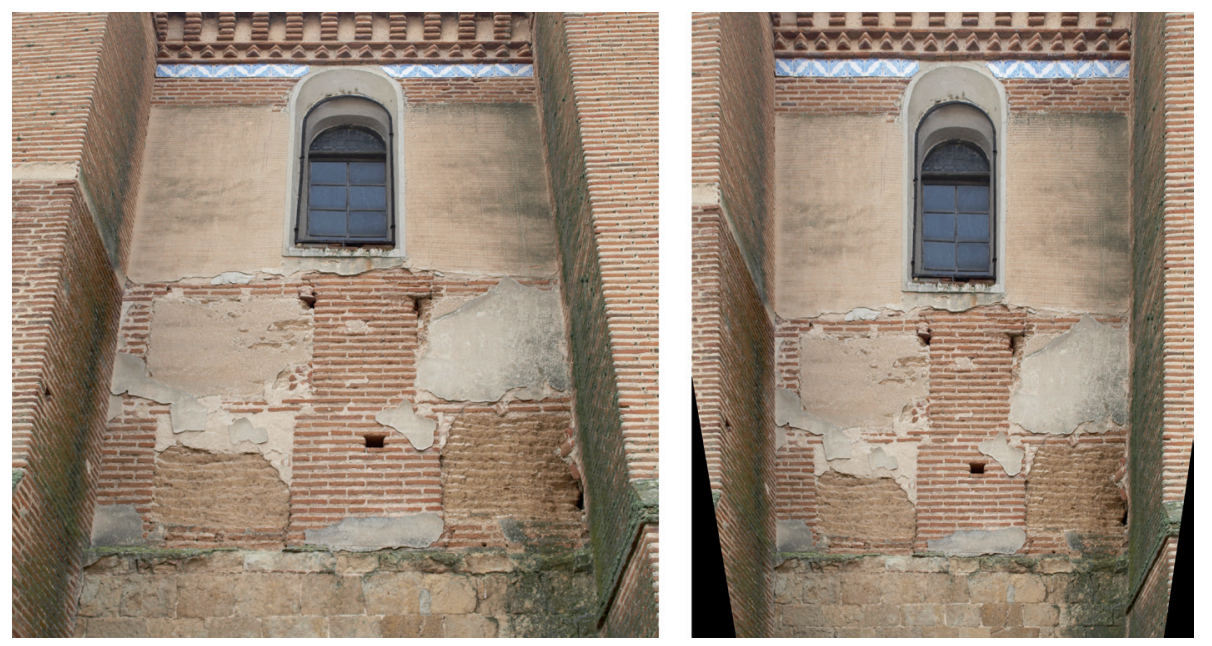

Figura 11. Imagen en perspectiva y rectificada de un paramento de la iglesia de Santa María (Alaejos).

A diferencia de la fotogrametría tridimensional, la rectificación aporta únicamente una imagen transformada de la original, de modo que los puntos o líneas han de delinearse manualmente sobre ella. Además, su aplicación queda limitada a objetos esencialmente planos, ya que no es posible rectificar elementos con otras formas tridimensionales. Puesto que tanto la base metodológica de la rectificación como los resultados que se obtienen son muy distintos respecto de la fotogrametría tridimensional, consideramos fundamental distinguir dichas técnicas en su terminología, evitándose confusiones al emplear el término genérico «fotogrametría».

\section{5.- Métodos complementarios}

Además de los procedimientos mencionados anteriormente, también creemos oportuno señalar algunos complementarios, con la idea de potenciar una concepción más amplia de la documentación gráfica del patrimonio construido, abierta a nuevas tecnologías.

En primer lugar, es ya conocido el empleo del georradar para el sondeo y análisis de estructuras edificadas bajo tierra (García 2003; Zamora, Pocoví y Pueyo 2005). Las emisiones lanzadas por este aparato hacia la tierra son reflejadas y rebotadas en distinto modo dependiendo de las características físicas de los materiales que se encuentre en su camino, de ahí que posibilite identificar distintos elementos en función de la penetración de las ondas. No obstante, los resultados son en ocasiones difusos e inciertos, por lo que suele emplearse en combinación con otras técnicas.

La termografía es una técnica que permite determinar las temperaturas superficiales de un objeto a distancia, sin necesidad de contacto directo (Cusidó 1996). El flujo de transmisión del calor desde el interior de los edificios hacia el exterior depende de las características de los materiales que componen sus paramentos. De este modo, mediante el empleo de cámaras termográficas es posible detectar cambios y degradaciones en los materiales gracias a las diferencias de temperatura superficial de la envolvente del edificio.

En relación con el aspecto anterior, hemos de mencionar el campo de investigación basado en las imágenes espectrales (Banerjee y Srivastava 2013). Del mismo modo que las cámaras termográficas captan las radiaciones infrarrojas (emisiones con frecuencias por debajo del espectro visible), las imágenes espectrales y multi-espectrales ofrecen información sobre las radiaciones emitidas en distintas frecuencias, las cuales pueden relacionarse con las propiedades de los materiales que conforman un determinado objeto.

\section{6.- Discusión comparativa de métodos}

La descripción sintética y aséptica de los métodos anteriormente expuesta queda corta en nuestra opinión si no se realiza a continuación una discusión crítica sobre los criterios de uso para la documentación gráfica del patrimonio construido. Por ello exponemos a continuación una serie de reflexiones propias basadas en nuestra experiencia, que en cualquier caso queda abierta a la discusión y que habrán de actualizarse con el desarrollo de las tecnologías de captura y gestión de datos (Figura 12).

\section{Tipos de resultados obtenidos}

Una vez establecidos los requisitos de la documentación gráfica (en función de los valores culturales materiales $\mathrm{y}$ de las necesidades de los trabajos posteriores), debe considerarse el tipo de resultados que cada método ofrece y las implicaciones relativas a la gestión de los datos 


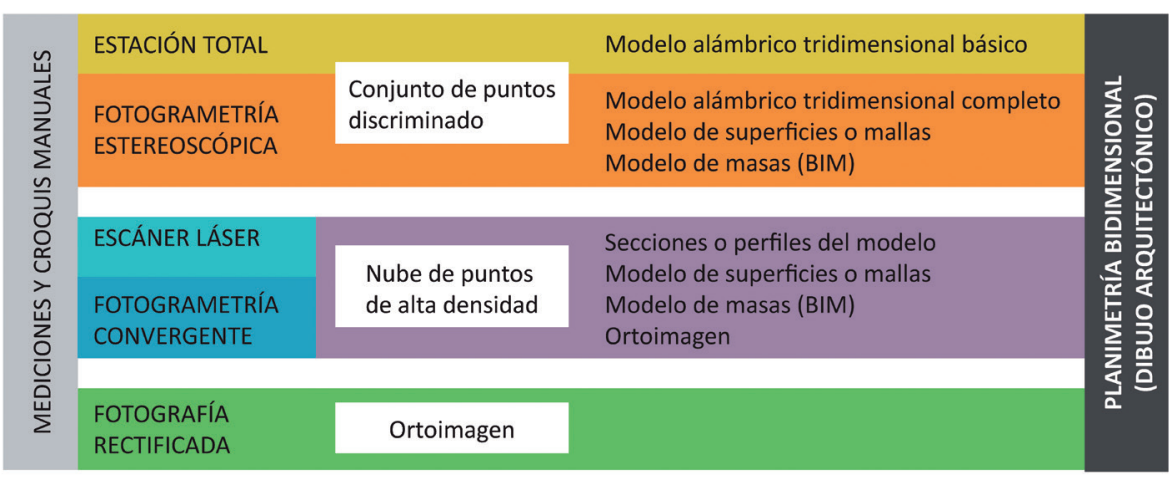

Figura 12. Tabla resumen de métodos y resultados. obtenidos. Al margen de las mediciones manuales, podemos señalar tres tipos básicos de resultados directos: conjunto de puntos discriminados, nubes de puntos de alta densidad y ortoimágenes.

En primer lugar, las mediciones selectivas con estación total aportan un conjunto de puntos discriminados (Figura 13). Ello implica que la cantidad de datos es sensiblemente menor que la obtenida con otros métodos y que dichos datos son todos ellos útiles y significativos para elaborar la documentación gráfica, por lo que su procesado en oficina es muy rápido. El resultado es un listado de puntos topográficos con sus coordenadas cartesianas, de muy fácil manejo, y que es altamente compatible con cualquier aplicación CAD usual, lo que le aporta una gran versatilidad. Como los puntos suelen definir las principales líneas geométricas del edificio, mediante la unión de dichos puntos puede obtenerse lo que se denomina modelo alámbrico tridimensional (Figura 14). Este modelo permite representar las directrices geométricas y formales del edificio, a partir de las cuales pueden elaborarse los dibujos planimétricos (plantas, secciones y alzados), todos ellos referidos a un único sistema de coordenadas. La característica fundamental de este tipo de modelos tridimensionales es que únicamente representan líneas, no superficies ni masas, lo que dificulta su visualización y entendimiento, pero al mismo tiempo son muy ligeros y fáciles de manejar.

Los modelos alámbricos tridimensionales obtenidos a partir de la medición con estación total suelen limitarse a las líneas geométricas principales, debido al elevado tiempo de campo que requeriría un modelo más completo que incorporase, por ejemplo, los despieces

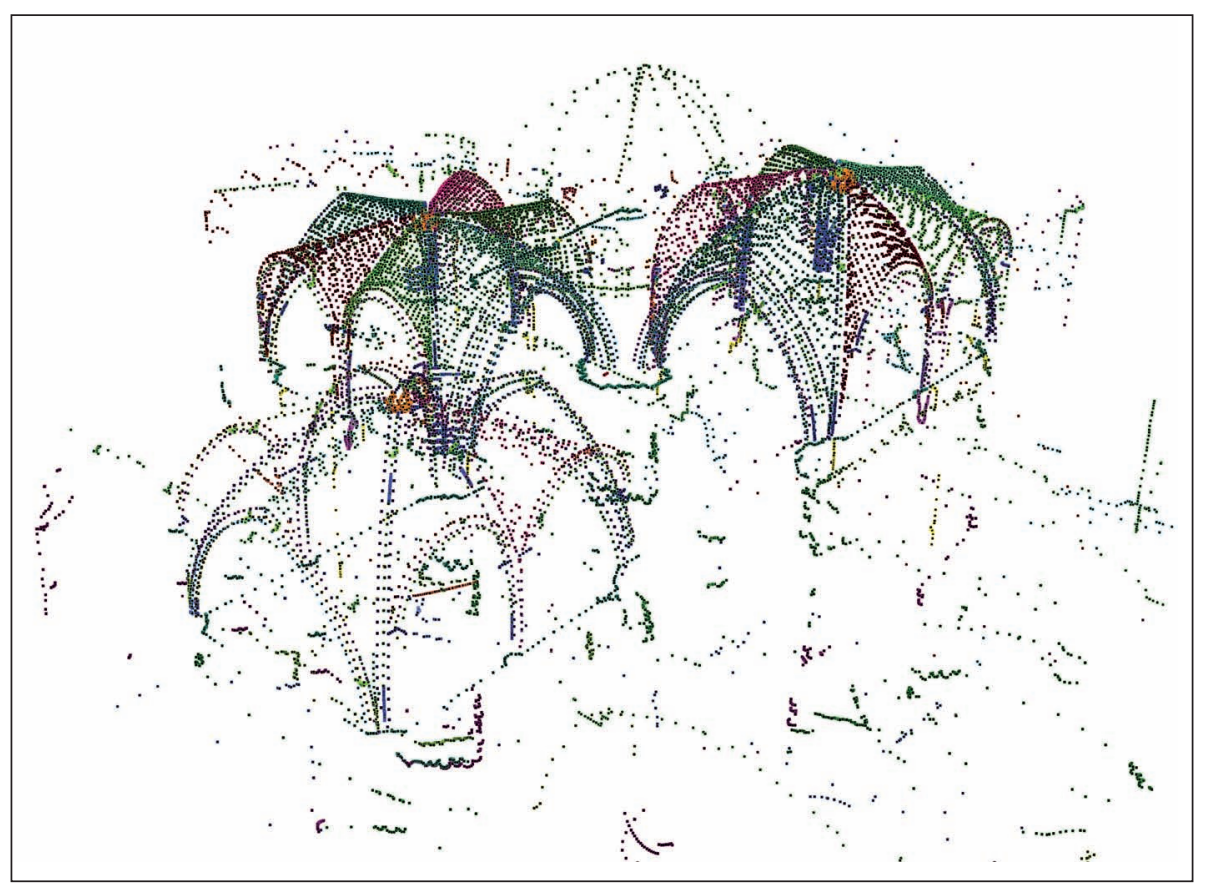

Figura 13. Levantamiento con estación total de las bóvedas sexpartitas del presbiterio y del brazo crucero de la catedral de Santa María (Sigüenza). Realización, Rocío Maira Vidal. Enjarje Arquitectura (www.enjarje.com). 


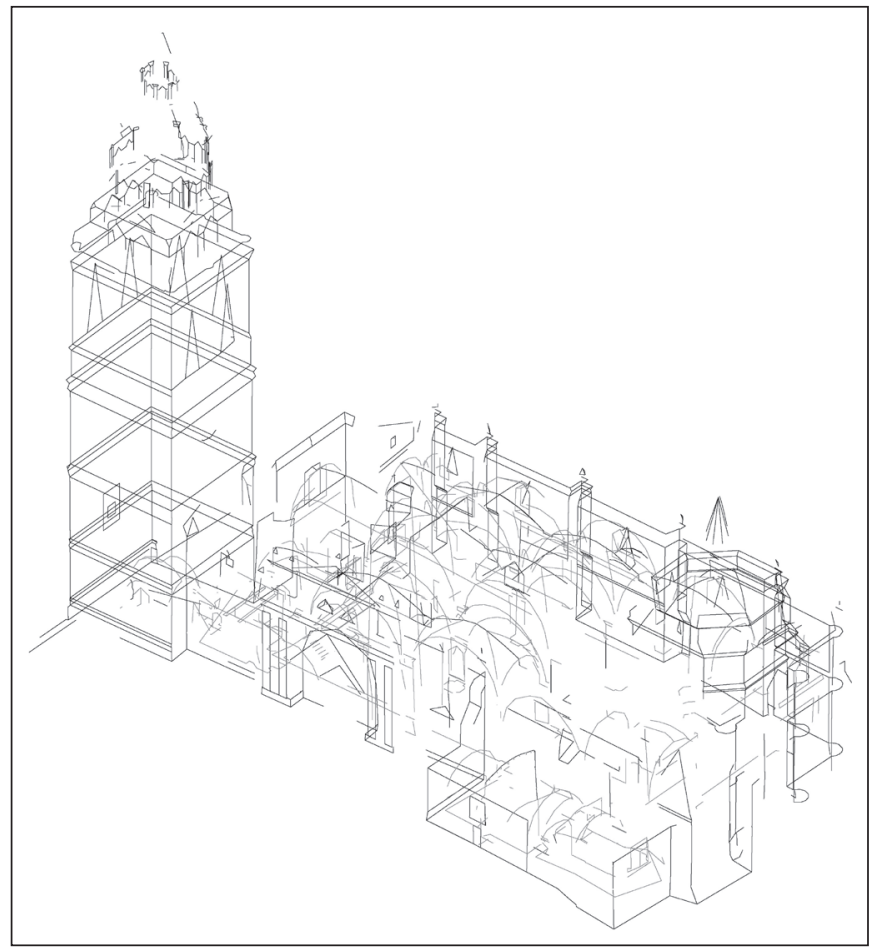

Figura 14. Modelo alámbrico tridimensional de la iglesia de Santa María (Alaejos).

de las fábricas. Al estar la información ya seleccionada y limitada, cualquier aumento o complemento de la misma requeriría un nuevo trabajo de campo con el coste adicional correspondiente, por lo que una adecuada selección inicial de los datos a medir es fundamental. Sin embargo, mediante el empleo de la fotogrametría estereoscópica, el registro de los datos es completo y se puede obtener un modelo alámbrico tridimensional con el nivel de detalle deseado (Figura 15). Además, en sucesivas fases de trabajo se puede completar dicho modelo en oficina sin tener que hacer una nueva toma de datos.

En segundo lugar, el empleo de escáner láser o fotogrametría convergente aporta nubes de puntos de alta densidad. La ventaja fundamental es que se realiza una toma de datos prácticamente completa y las posteriores ampliaciones de la documentación gráfica no necesitan de nuevas tomas de datos. Sin embargo, al no seleccionarse los datos en campo, la información obtenida es muy elevada, por lo que su manejo posterior es muy complejo y necesita aplicaciones informáticas específicas. Las nubes de puntos de alta densidad presentan por lo tanto una doble vertiente en relación con su uso, debido a la gran cantidad de información que contienen por un lado y a la dificultad de su manejo por otro. Además,

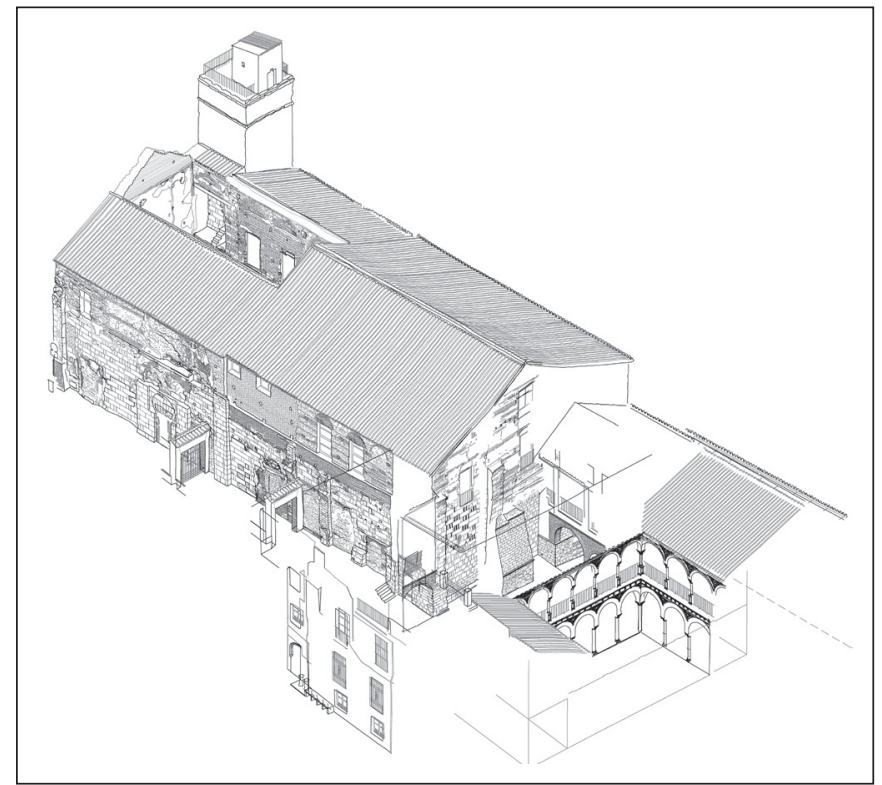

Figura 15. Modelo alámbrico tridimensional completo de la iglesia del convento de Santa Clara (Córdoba). Fundación Caja Madrid. Realizado por Latorre y Cámara, S.L.

en el caso del método de la fotogrametría convergente, la obtención de la nube de puntos no es para nada inmediata a partir de las fotografías y el proceso hasta lograr un resultado satisfactorio suele ser largo y complejo.

La nube de puntos de alta densidad contiene una gran cantidad de información en bruto, tanto las coordenadas cartesianas de los puntos como generalmente también su color. A partir de ellas puede elaborarse una documentación gráfica de alta definición. Sin embargo, por sí mismas no constituyen un documento o modelo susceptible de ser empleado directamente; si bien en una vista general pueden apreciarse formas y volúmenes con claridad, al acercar el punto de vista se pierden los elementos y es imposible reconocer aristas o superficies, ya que no están destacados o seleccionados los puntos principales que las definen (Figura 16) Por lo tanto, es imprescindible un procesado de los datos, como la obtención de perfiles o la elaboración de modelos tridimensionales de mallas o masas.

La operación más inmediata que se puede realizar con una nube de puntos de alta densidad es la obtención de cortes horizontales o verticales, seleccionando dos planos paralelos relativamente cercanos que delimitan un conjunto de puntos y excluyen el resto. El resultado es equivalente al perfil horizontal o vertical del edificio en una determinada posición. Sin embargo, dista mucho de convertirse directamente en una planta o sección propiamente dicha. En primer lugar, porque estos documentos 


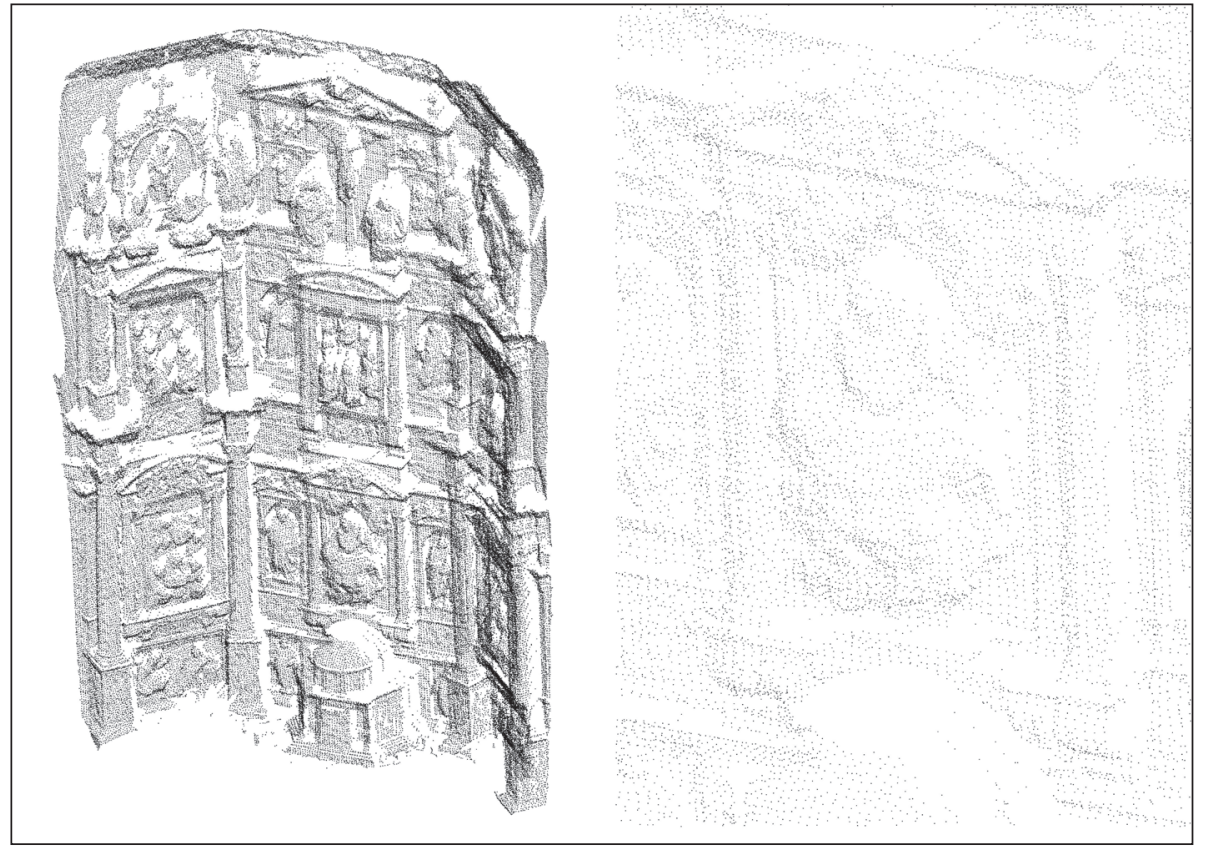

Figura 16. Nube de puntos en la iglesia de Santa María (Alaejos). Vista general a la izquierda y detalle a la derecha. arquitectónicos incluyen más información que el corte estricto, como son los objetos proyectados por delante o por detrás del plano de corte. Y en segundo lugar, porque una planta o una sección son interpretaciones que describen formal y constructivamente el edificio, mientras que el conjunto de puntos no ofrece información sobre cómo está construido dicho edificio. Una vez más, no debemos confundir ni pretender equiparar una serie de datos objetivos en bruto con un dibujo de arquitectura. Como ya hemos señalado, la representación gráfica de los edificios implica necesariamente un proceso subjetivo de análisis, interpretación y plasmación gráfica de las características constructivas de los mismos. Aunque existen opiniones que abogan por la virtud de los datos objetivos, sin tratamiento alguno (García-Gómez, Fernández de Gorostiza y Mesanza 2011: 35), creemos firmemente que una parte importante de la representación gráfica debe seguir siendo la expresión constructiva y formal del edificio, con una carga analítica e interpretativa sin la cual el documento gráfico queda incompleto y no cumple sus objetivos.

Además de estos cortes, a partir de una nube de puntos de alta densidad es posible generar un modelo de superficies o mallas, que suponen un avance en la materialización física del edificio. El proceso de mallado puede describirse en términos generales como la generación de superficies triangulares planas entre conjuntos de tres puntos, llegándose a crear superficies completas asimilables a las de los objetos reales. Este tipo de modelo permite tapar las partes ocultas desde un determinado punto de vista, facilitando en gran medida su comprensión espacial. Además, puede determinarse un único plano de corte (no dos, como en el caso anterior), que proporciona un perfil mucho más definido. Puesto que los puntos poseen generalmente información de color, los triángulos planos pueden generarse con un valor intermedio del color de los tres vértices, aumentando el realismo del modelo.

El nivel más avanzado en el desarrollo de modelos tridimensionales de edificios se consigue al generar objetos con entidad material propia, es decir, elementos sólidos internamente y definidos por sus superficies externas, con las propiedades físicas de los objetos reales que representan (muros, pilares, vigas, bóvedas, etc.). Actualmente se conoce esta técnica como BIM (Building Information Modeling), o modelados con información constructiva, y están muy extendidos en el ámbito de los proyectos de edificación de nueva planta (Angulo 2012). Sin embargo, su aplicación a edificios históricos presenta todavía considerables limitaciones, derivadas de la naturaleza irregular y deformada que casi todos presentan, lo que hace complejo un tipo de modelización sistematizada.

El tercer y último tipo de resultado que hemos considerado son las denominadas ortoimágenes. A diferencia de las fotografías, que representan una perspectiva cónica sobre la que no se pueden obtener medidas ni proporciones directas, la ortoimagen consiste en una proyección ortogonal del edificio sobre un plano previamente definido y que suele estar orientado según el elemento a representar 


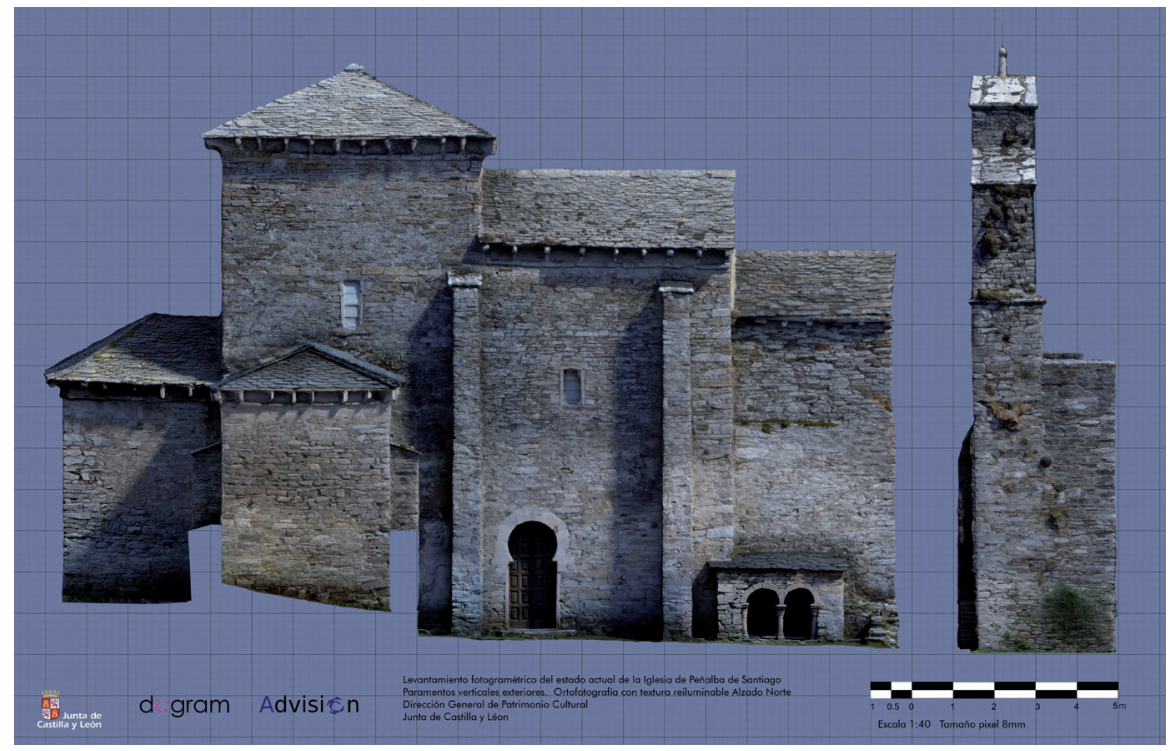

Figura 17. Alzado norte de la iglesia de Santiago de Peñalba (Peñalba de Santiago). Dirección General de Patrimonio Cultural. Junta de Castilla y León. Realización, Dogram. (por ejemplo, una fachada). De este modo, se consigue un resultado que combina la determinación métrica de un plano a escala con la información de una imagen (texturas, colores, etc.).

La obtención de una ortoimagen puede conseguirse mediante dos vías. Por un lado, mediante la proyección sobre un plano de la parte vista de una nube de puntos de alta densidad o de un modelo de mallas (Figura 17). Así, los puntos tridimensionales con color se convierten en los pixeles de la ortoimagen y, una vez más, el factor densidad se convierte en crucial para la calidad de la imagen resultante. No obstante, la obtención de una adecuada ortoimagen a partir de una nube de puntos dista mucho de ser un proceso sencillo e inmediato, ya que es preciso dotar de una buena iluminación al edificio y evitar así las zonas ocultas producidas por elementos intermedios.

El método más sencillo para obtener ortoimágenes es la fotografía rectificada. Como ya se ha comentado, este proceso distorsiona las imágenes fotográficas originales en perspectiva para transformar una parte plana de ellas en proyección ortogonal. Sin embargo, este método necesita de un apoyo métrico, generalmente con una base topográfica, por lo que no es autónomo en sí mismo. Además, su aplicación se limita a elementos esencialmente planos, si bien es cierto que la gran mayoría de los objetos arquitectónicos son o pueden descomponerse en superficies planas (Figura 18).

En cualquier caso, sea cual sea el método de toma de datos empleado y el resultado directo obtenido, en general la documentación gráfica debería estar constituida por el conjunto de dibujos planimétricos (plantas, alzados y secciones). Queremos destacar este aspecto ya que, si bien los modelos tridimensionales son potentes e insustituibles herramientas para el conocimiento y la difusión de los bienes patrimoniales, el dibujo de arquitectura sigue siendo la base fundamental para la documentación gráfica y el desarrollo de trabajos y estudios sobre el edificio. Entendemos por un lado que el dibujo,

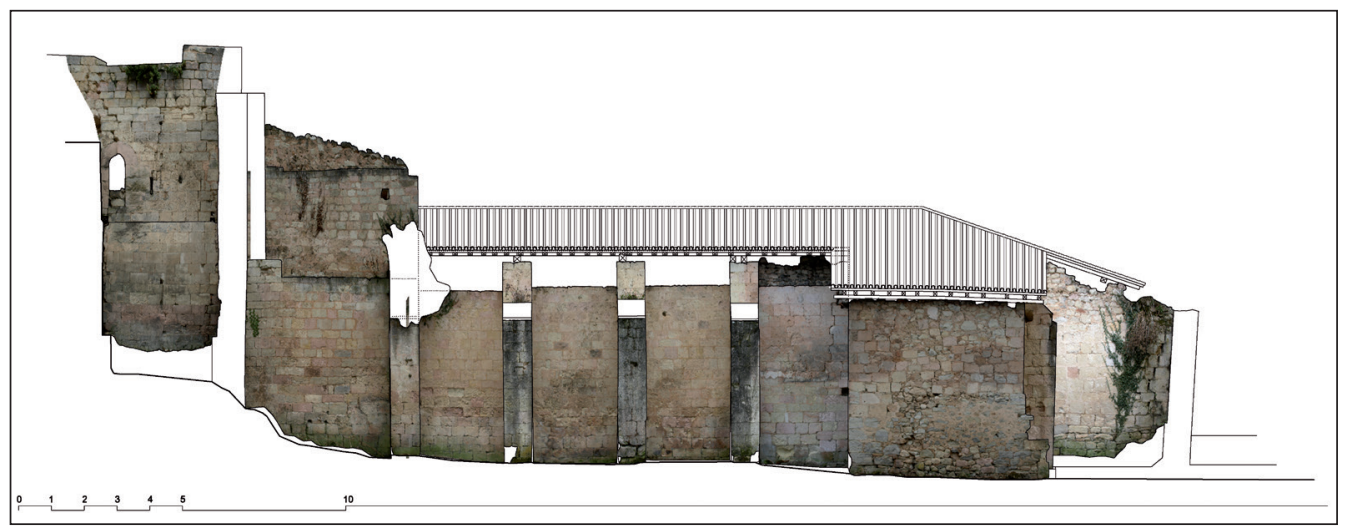

Figura 18. Ortoimagen con fotografía rectificada del alzado occidental del claustro de la colegiata de Santa María (Valpuesta). 
al implicar una interpretación formal y constructiva, supone un filtro que traduce los datos geométricos abstractos en un lenguaje comprensible por todos los futuros usuarios. Además, el formato de la planimetría junto con la estrategia de correspondencia planta-alzado-sección es, a día de hoy, la herramienta más versátil y eficaz para transmitir y manejar la información geométrica y constructiva sobre el edificio.

\section{Recursos necesarios, procesado de los datos y tiempos de ejecución}

Uno de los aspectos fundamentales a la hora de seleccionar un determinado método de toma de datos para la elaboración de la documentación gráfica son los recursos materiales y humanos necesarios en cada uno de ellos. Al margen de las mediciones manuales, los tres grandes grupos que podemos establecer en función de los recursos necesarios son la medición con estación total y el apoyo de la fotografía rectificada, el escáner láser y la fotogrametría tridimensional. Sea cual sea el método, para elaborar una documentación gráfica de un edificio completo, en general es necesario disponer de una base geométrica global, de modo que suele ser necesario el empleo de dispositivos topográficos.

La toma de datos con estación total aporta directamente dicha base geométrica común. Este método demanda unos recursos materiales relativamente reducidos, puesto que el equipo necesario tiene un precio muy asequible tanto en modo alquiler como en venta. Sin embargo, el tiempo de campo requerido es el mayor de los tres grupos, debido a la medición individualizada de cada punto. Además, generalmente se requieren dos personas, especialmente cuando se realizan mediciones con prisma. Este mayor trabajo en campo se compensa con una menor necesidad de horas en oficina, puesto que el volcado de los datos es prácticamente inmediato y los puntos obtenidos ya están seleccionados, por lo que la delineación del modelo alámbrico y una planimetría básica se consigue con la mayor rapidez de todas las técnicas. Si además se quiere documentar más información (como los despieces de las fábricas), es preciso combinar con técnicas como la fotografía rectificada, por lo que aunque el tiempo en campo no aumenta significativamente, sí se incrementan las horas de oficina, tanto para la rectificación como para la delineación. En cualquier caso, el software específico para la rectificación es asequible y sencillo de manejar.

El empleo del escáner láser reduce muy significativamente el tiempo de toma de datos en campo. Sin embargo, el coste en venta o alquiler de un escáner láser es muy superior al de una estación total básica. Además, aunque se pueden encadenar las distintas tomas de láser mediante elementos de referencia (bolas, dianas, etc.), en general es aconsejable apoyar la captura en una base topográfica obtenida con estación total, especialmente en levantamientos de edificios enteros por el interior y el exterior, con el consiguiente aumento de coste y la dificultad del manejo de dos dispositivos. Por ello, es recomendable la presencia de dos personas.

El trabajo en oficina con una nube de puntos de alta densidad es una labor con claras ventajas, pero también conlleva serios inconvenientes. La disponibilidad de tal cantidad de información hace posible obtener una documentación gráfica muy completa. Sin embargo, su manejo requiere por un lado de equipos informáticos con una elevada potencia de procesamiento y, por otro, aplicaciones específicas generalmente vinculadas a la casa comercial del escáner láser. El procesado de los datos de nubes de puntos incluye tanto la inclusión de todas las tomas en un único sistema de referencia, la generación de mallas trianguladas, la realización de cortes singulares y la proyección sobre planos para obtener ortoimágenes. La compatibilidad de los datos obtenidos con aplicaciones usuales de CAD no es siempre adecuada, haciendo más complejo el proceso. A todo ello se le une el proceso de generación de ortoimágenes y la posterior delineación necesaria para obtener una documentación gráfica completa. Ello hace que la ventaja de tiempos en la toma de datos contraste con un mayor tiempo en oficina respecto al empleo de la estación total combinada con la fotografía rectificada. En cualquier caso, creemos que algunos problemas podrán irse solventando con el desarrollo de las distintas aplicaciones informáticas, especialmente aquellas de uso abierto y compatible con los distintos formatos de datos.

Finalmente, los métodos basados en la fotogrametría tridimensional sólo demandan a priori el empleo de cámaras fotográficas para la toma de datos, así como instrumentos para obtener medidas de apoyo, abaratando notablemente el proceso. Sin embargo, de cara a obtener una documentación rigurosa de un edificio completo es prácticamente imprescindible el apoyo topográfico de una estación total que integre todos los datos en un mismo sistema de referencia, con el consiguiente aumento de costes y tiempos. No obstante, este tipo de técnicas son las que requieren en general un menor tiempo de toma de datos en campo. 
En contraste, la fotogrametría tridimensional demanda un procesado de datos en oficina que en general es mayor que con las técnicas anteriormente citadas. En el caso de la fotogrametría estereoscópica, el delineado tridimensional de los distintos elementos es largo y complejo, comparado con el dibujo sobre una ortoimagen plana. Además, los recursos necesarios en oficina (estereoscopios o monitores estereoscópicos y gafas polarizadas, así como las correspondientes aplicaciones informáticas) son los más costosos de todas las técnicas.

Frente a este método, la fotogrametría convergente demanda en oficina únicamente las aplicaciones informáticas correspondientes. Sin embargo, el procesado de las imágenes es también largo y en ocasiones complejo, aunque indudablemente más barato que el empleo del escáner láser. Es cierto que esta labor varía en función de cada aplicación, y posiblemente la evolución de las mismas contribuya a una optimización del proceso en oficina. Nuestra experiencia con herramientas como Orthoware (www.orthoware.com) nos señala que es necesario realizar varios procesos iterativos de generación de nubes de puntos y mallado con sus correcciones, además de tener que montar casi manualmente un mosaico final para obtener ortoimágenes, lo cual dificulta la obtención de resultados satisfactorios. En este sentido, creemos que Photoscan (www.agisoft.ru/products/photoscan) ha logrado una mejora en el procesado de los datos, más intuitivo y sencillo. No obstante, estimamos que el tiempo necesario para la obtención de una correcta nube de puntos de un edificio completo es superior al que se emplea con el escáner láser. Al margen dejamos aplicaciones web como 123D Catch (www.123dapp.com/catch) o $\operatorname{Arc3D}$ (www.arc3d.be) las cuales sin duda proveen los resultados más rápidos de todo el conjunto de técnicas. Sin embargo, puesto que el procesado de los datos es realizado sin control ni supervisión alguna del autor del trabajo, creemos que no debe emplearse para la realización de planimetrías que aspiren a un rigor métrico y documental como las que en este artículo se tratan. Sin embargo, sí pueden ser herramientas muy útiles para la visualización rápida y sencilla de edificios.

\section{Criterios básicos para la selección de métodos}

En primer lugar, es necesario recalcar que los métodos expuestos no dejan de ser herramientas que tienen una finalidad, la cual debe ser necesariamente el criterio principal de cara a la elección del método. Para definir el alcance de la documentación gráfica, es preciso considerar tanto los valores culturales materiales del edificio como los posteriores trabajos a desarrollar, tal y como se ha expuesto anteriormente. Además, los recursos disponibles son otro factor fundamental a la hora de seleccionar un método y la optimización de los mismos un objetivo en todos los casos. Así, la finalidad de la documentación, los valores culturales del edificio y los recursos disponibles constituyen los tres elementos básicos para la toma de decisiones.

A partir de aquí, la cuestión radica en el tipo de resultado que se desea obtener, lo cual está directamente relacionado con la finalidad de la documentación. De este modo, cuando se pretenda obtener una documentación básica de la geometría del edificio, se podrá optar por la medición con estación total de un conjunto de puntos discriminado y elaborar el modelo alámbrico básico, a partir del cual se puede obtener la planimetría y además permite registrar deformaciones y movimientos de las fábricas gracias a dicho modelo tridimensional. Si además se requiere mayor nivel de detalle en elementos planos (revestimientos, despieces, pavimentos, etc.), se puede complementar con fotografía rectificada para obtener ortoimágenes sobre las que delinear. Así, la combinación de medición con estación total y fotografías rectificadas constituye uno de los métodos más versátiles y económicos.

Los casos en los que se requiera un modelo tridimensional completo, especialmente cuando existan elementos de geometrías no planas que se deseen documentar en su forma tridimensional, será necesario recurrir al escáner láser o la fotogrametría tridimensional. En este caso, la elección consiste en obtener nubes de puntos de alta densidad (con escáner láser o fotogrametría convergente) o un modelo alámbrico completo (con fotogrametría estereoscópica). Como ya se ha comentado, la nube de puntos contiene una elevada cantidad de información y, si bien su obtención es rápida, su procesado hasta la obtención de la documentación gráfica es complejo y lento. Por su parte, la fotogrametría estereoscópica requiere una toma de datos y un procesado más lentos, aunque el modelo tridimensional que se obtiene es más útil que la nube de puntos de alta densidad, ya que a partir de ella es necesario recurrir a la proyección en ortoimágenes o al modelado de superficies o de masas para poder sacar partido a dicha información, y ninguno de los procesos es rápido ni sencillo. En definitiva, creemos que, si es posible, se debería optar por la fotogrametría estereoscópica, ya que el resultado final es mucho más útil, comprensible y manejable que la nube de puntos de alta densidad, gracias sin duda al proceso 
de análisis, interpretación y síntesis que requiere la delineación del modelo tridimensional completo.

No obstante, desde nuestra experiencia, y teniendo siempre en cuenta los criterios generales enunciados anteriormente, creemos que no existe un método óptimo universal, sino que la adecuada combinación de ellos permite ajustarse mejor a las necesidades y a los recursos disponibles. En este sentido, la estación total ofrece una base geométrica de referencia imprescindible en casi todos los casos. Con dicha base sólidamente establecida, las distintas técnicas se podrán además combinar sin problemas, permitiéndonos responder a los objetivos planteados con un equilibrado planteamiento de recursos.

\section{4.- CASOS DE ESTUDIO}

Para finalizar esta exposición de ideas, destacamos a continuación los aspectos más relevantes de algunos trabajos realizados, enfatizando los criterios concretos de selección de los métodos empleados.

\section{1.- Iglesia de Nuestra Señora de Campanario (Almazán)}

En el primero de los casos aquí mostrados se trataba de elaborar la planimetría completa del templo, incluyendo sus plantas, secciones y alzados, con el objetivo de documentar el bien cultural y servir como herramienta para las actividades de investigación, conservación y difusión.

El edificio, construido con sillería y mampostería, presenta unas dimensiones amplias, con tres naves de cuatro tramos, crucero y cabecera con triple ábside semicircular. Además del exterior y el interior de las naves, se requería la documentación de una serie de espacios bajocubierta de difícil acceso. Mientras que el exterior presenta sus fábricas vistas, el interior (exceptuando el crucero y la cabecera) está completamente revestido.

Con estas premisas, se optó por el empleo de una estación total para obtener un conjunto de puntos discriminado que representan los principales elementos geométricos del edificio. Con dichas mediciones pudo elaborarse la planimetría completa e integrada en un único sistema de referencia, incluidos los espacios bajocubierta de difícil acceso, gracias a la versatilidad que permite el empleo de la estación total y la relación entre los distintos puntos de estacionamiento. De este modo se estableció un itinerario principal exterior y dos itinerarios interiores (uno para el nivel del suelo y otro en el bajocubierta). A partir de los puntos medidos se elaboró el modelo alámbrico básico que permitió dibujar cada uno de los planos. Puesto que además de la información geométrica básica se requería la delineación de los despieces de las fábricas vistas, se decidió complementar el trabajo con fotografías rectificadas, de modo que al estar apoyadas topográficamente con la estación total, quedaron integradas en el mismo sistema de referencia que el resto de puntos (Figura 19).

Cabe destacar la elevada versatilidad de la combinación de la medición con estación total y la técnica de fotografía rectificada apoyada topográficamente e integrada en el mismo sistema de referencia. Sin requerir de unos elevados recursos, permite obtener una documentación de casi todos los elementos del edificio, incluso en situaciones complicadas, como los espacios bajocubierta de los edificios. Entendemos por ello que es actualmente un método con una de las mejores relaciones entre calidad y coste.

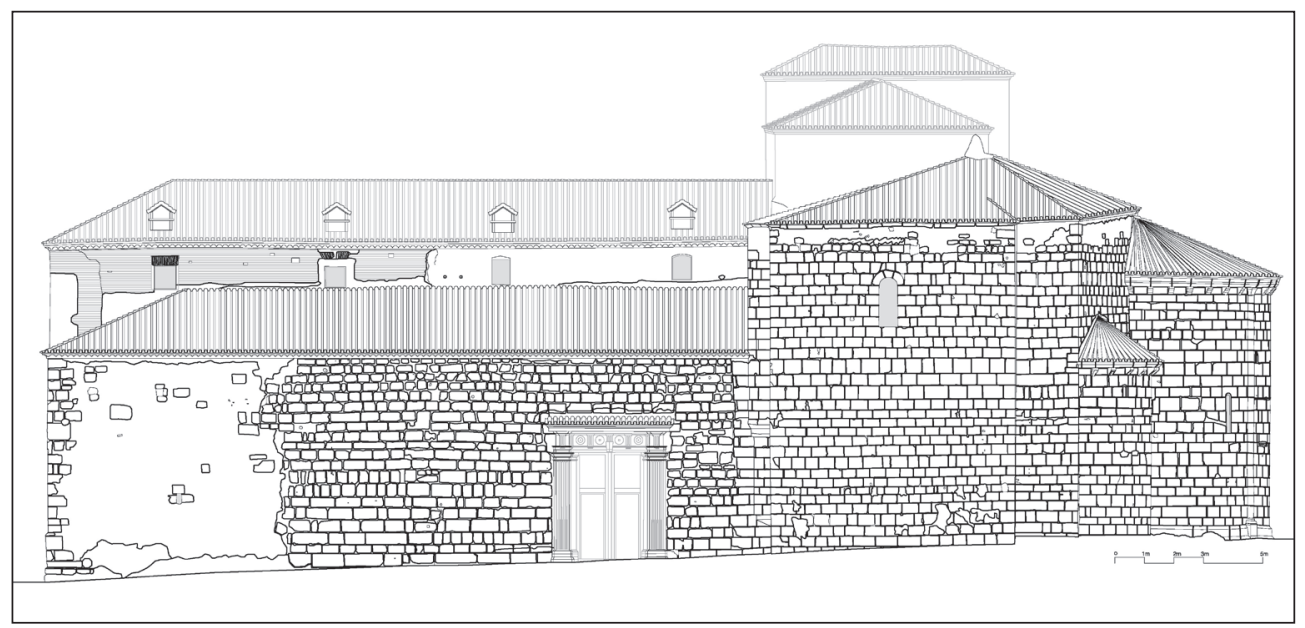

Figura 19. Alzado sur de la iglesia de Nuestra Señora de Campanario (Almazán). 


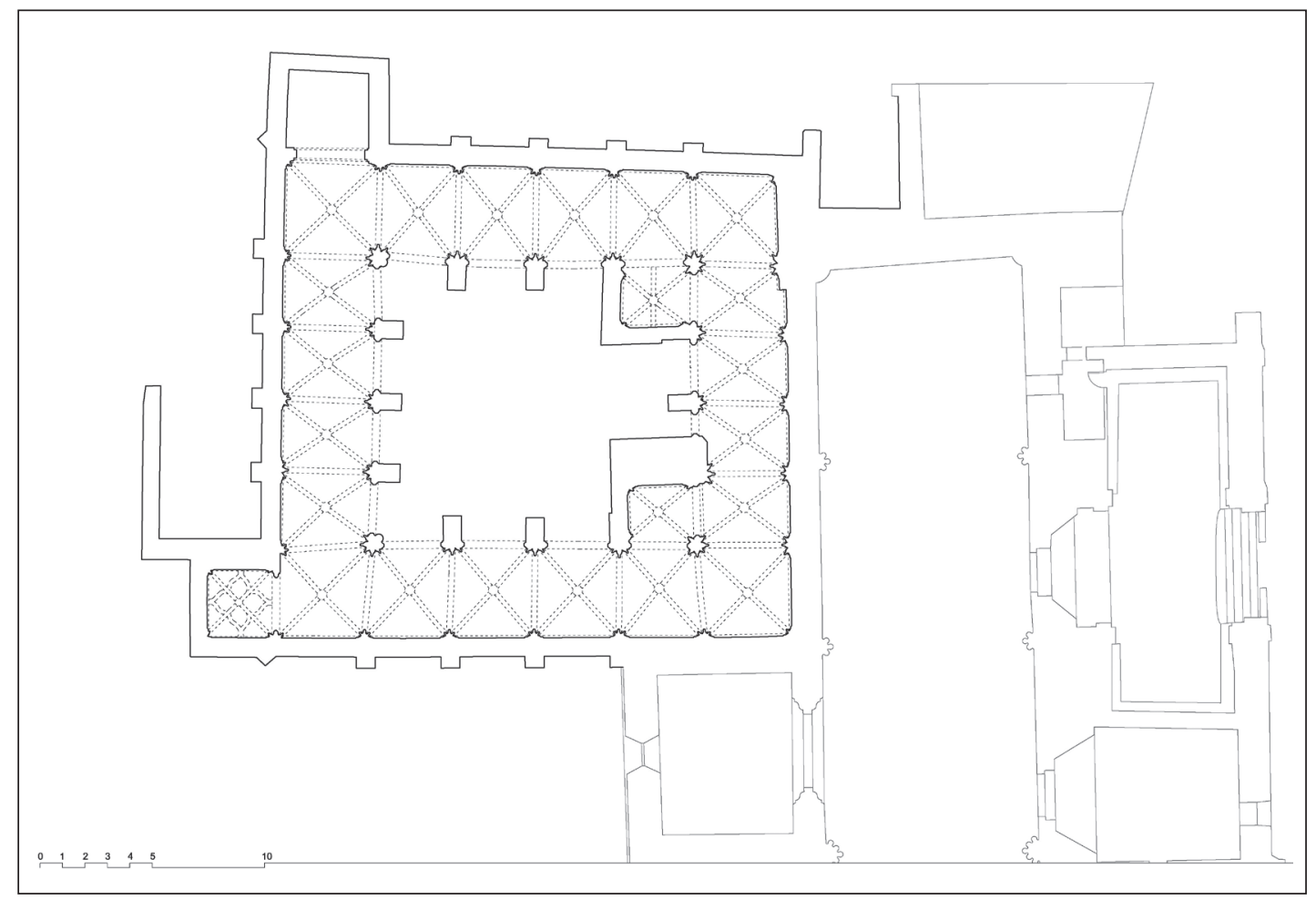

Figura 20. Planta del claustro de la colegiata de Santa María (Valpuesta).

\section{2.- Claustro de la Colegiata de Santa María (Valpuesta)}

Dentro del programa de restauración de la Colegiata, se iba a abordar la intervención en el claustro, para lo cual era necesario disponer de planimetrías adecuadas incluyendo el interior y el exterior del mismo. Además, se requería un registro exhaustivo de las deformaciones de todos los muros y bóvedas para el posterior análisis estructural, de cara a determinar las soluciones más idóneas para la restauración.

El edificio, adosado al templo, presenta una planta aproximadamente cuadrada, con seis tramos en cada lado, además de dos capillas en el interior y otras dos adosadas al exterior del muro perimetral. Además, una gran cantidad de tramos están tabicados con cierres de ladrillo a modo de apeo temporal. La fábrica está construida con sillería y mampostería, además de los tejados de madera que cubren las cuatro pandas del claustro. El trazado de la planta presenta notables irregularidades en sus dimensiones y alineaciones que habían de ser registradas, del mismo modo que los desplomes de los muros y la deformación de los nervios de las bóvedas (Figura 20). Sin embargo, no se iba a desarrollar ninguna investigación que demandara la delineación de los despieces de las fábricas, por lo que se consideró suficiente con la obtención de un modelo alámbrico tridimensional básico con todas las aristas de muros, estribos y bóvedas.

De este modo, atendiendo a las necesidades y recursos disponibles, se optó una vez más por el empleo de una estación total para medir selectivamente los puntos que definen los principales elementos constructivos del claustro y que permitió obtener el modelo alámbrico correspondiente a partir del cual dibujar las plantas, secciones y alzados (Figura 21). Aunque no se necesitaba la

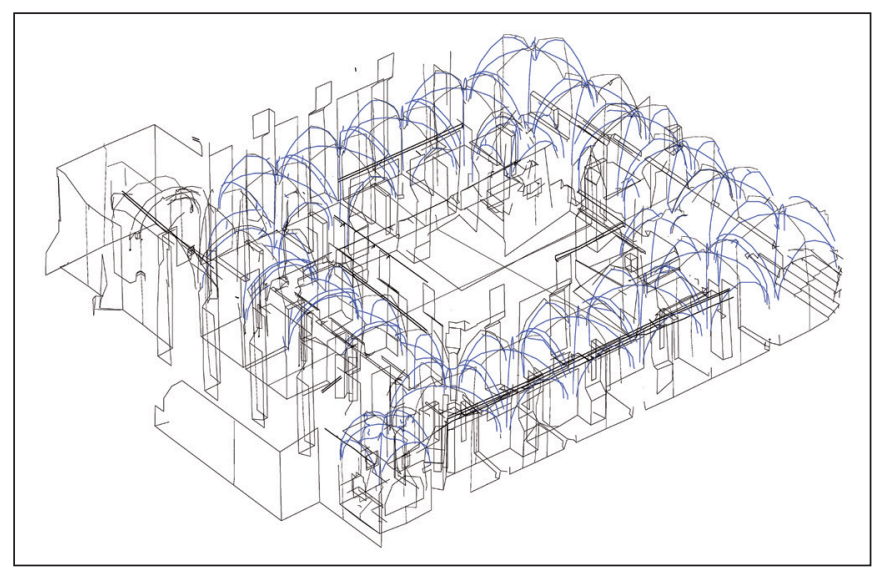

Figura 21. Modelo alámbrico tridimensional del claustro de la colegiata de Santa María (Valpuesta). 


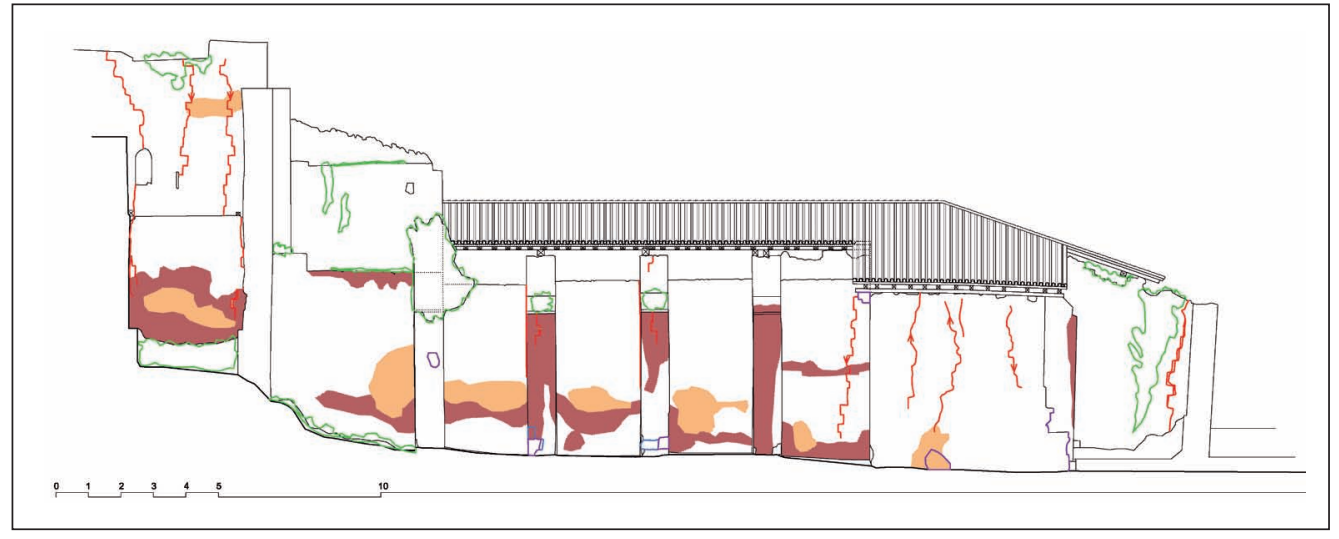

Figura 22. Alzado occidental del claustro con lesiones patológicas de la colegiata de Santa María (Valpuesta). delineación de los despieces de las fábricas, entendimos conveniente realizar tomas fotográficas de los paramentos exteriores para abordar su rectificación apoyada en los datos topográficos. Así, aunque no se dibujaron los despieces, se obtuvieron fácilmente las ortoimágenes de cada alzado exterior, posibilitando su futura delineación si fuese necesario. Además, estas ortoimágenes permitieron señalar las distintas lesiones superficiales en los paramentos (Figura 22).

La mayor dificultad en este caso consistió en la extrema división de los espacios interiores (tabicados muchos de ellos) que obligó a establecer una estación en cada tramo del claustro, con un total de 25 . Se demuestra así la versatilidad de este sistema, que se puede adaptar con relativa sencillez a espacios cerrados y fragmentados.

\section{3.- Iglesia de Santa María (Alaejos)}

Como contrapunto a los casos anteriores, queremos destacar en este el trabajo realizado para obtener una planimetría completa, con la geometría básica del edificio y los elementos constructivos de los paramentos, así requerida por las labores posteriores correspondientes a la lectura de paramentos y al proyecto de intervención.

La iglesia de Santa María es una construcción casi íntegra de fábrica de ladrillo, con unas notables dimensiones en planta, de tres naves, cabecera recta y un crucero que no se destaca al exterior. Uno de los elementos más significativos es su torre, con una altura muy elevada, y que, junto con la vecina del templo de San Pedro, configuran los hitos urbanos en la silueta del municipio.

Para abordar la documentación gráfica se optó, una vez más, por el empleo de una estación total y la medición discriminada de los puntos singulares del edificio, de cara a obtener un modelo alámbrico tri- dimensional básico. Además, la combinación con la fotografía rectificada apoyada en las mediciones topográficas permitió obtener ortoimágenes de los alzados exteriores, aportándose una documentación completa del edificio (Figura 23).

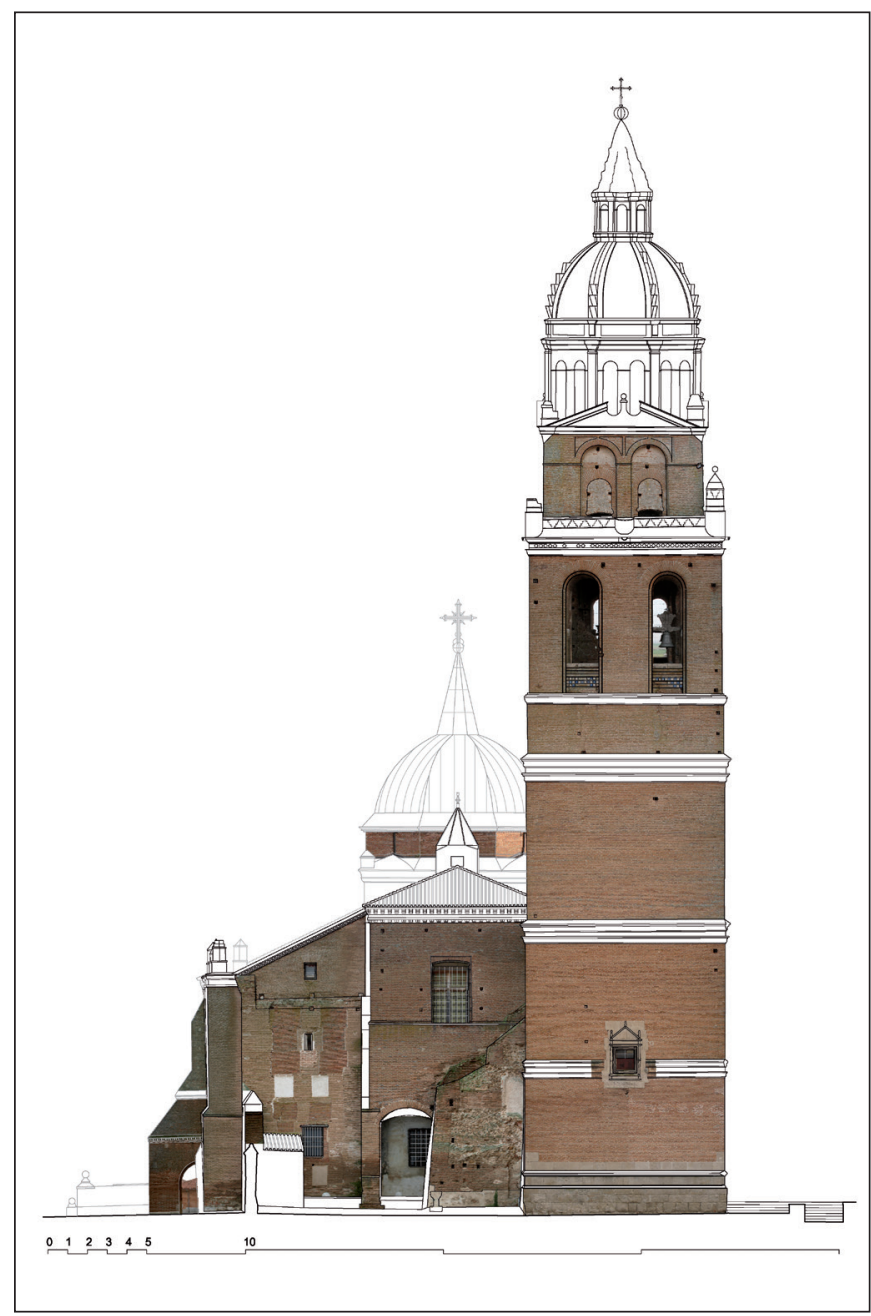

Figura 23. Alzado occidental con ortoimagen delineada de la iglesia de de Santa María (Alaejos). 


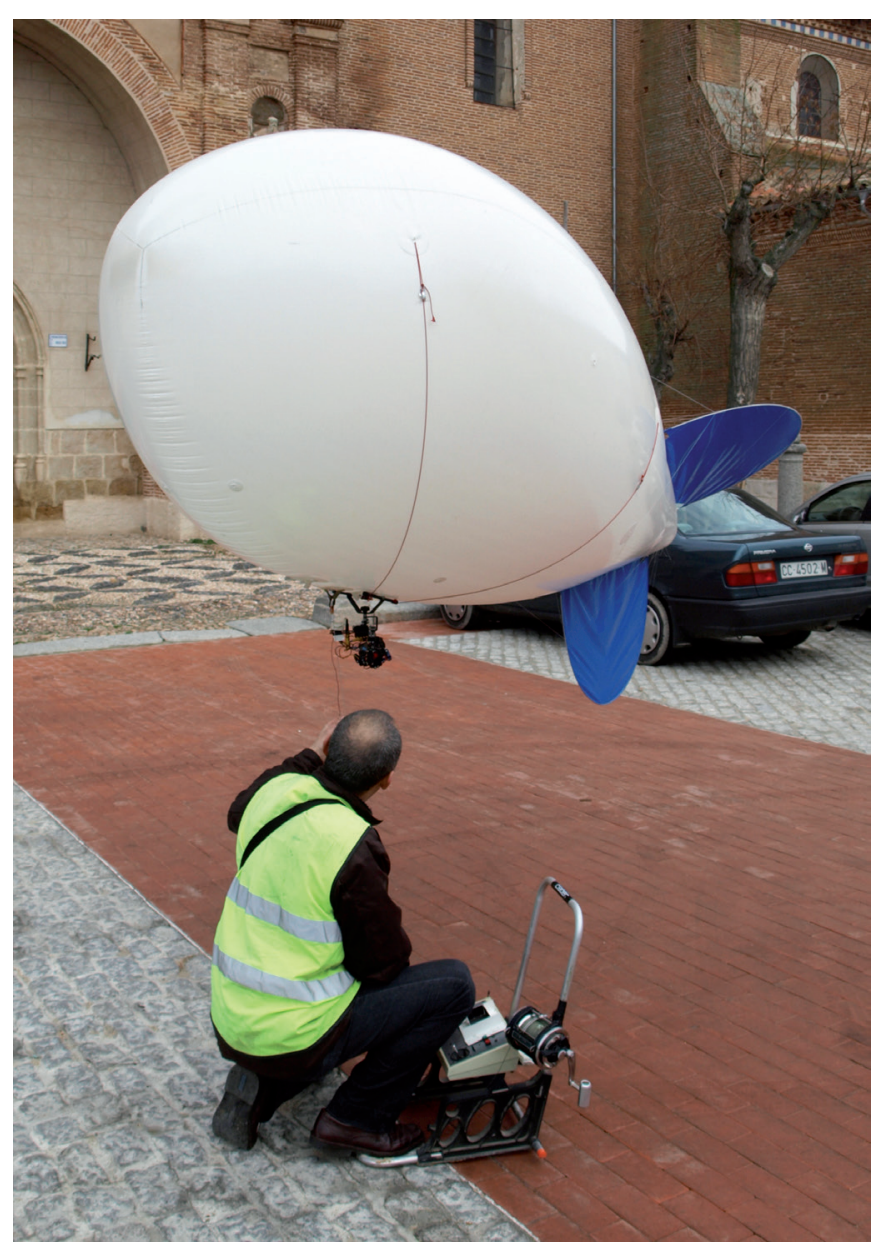

Figura 24. Dispositivo aéreo para la toma de fotografías en la iglesia de de Santa María (Alaejos)

Dos fueron en este caso los condicionantes más destacados. En primer lugar, la elevada altura de la torre, que forzaba a realizar tomas fotográficas para rectificar con direcciones excesivamente oblicuas respecto de los paramentos en sus zonas más altas. Si bien la técnica de la rectificación no obliga a que las tomas se realicen con total perpendicularidad a los elementos planos, sí es conveniente ajustarse lo más posible a esta condición. Por ello las imágenes de las partes altas de la torre, tomadas desde el suelo, no iban a ofrecer un buen resultado. En consecuencia, se optó por instalar la cámara fotográfica en un dispositivo aéreo controlado remotamente, gracias al cual se fueron realizando las tomas en condiciones mucho mejores, obteniéndose un resultado final satisfactorio (Figura 24). Es destacable la versatilidad de este sistema, ya que la toma de fotografías puede realizarse sobre grúas, plataformas elevadoras o aparatos voladores, sin que la calidad se resienta, mientras que el apoyo topográfico se hace desde el suelo. Esto no sería posible con dispositivos como el láser escáner, que se vería afectado por la más leve vibración, de modo que la toma debería hacerse desde el suelo, con la consecuente aparición de zonas de sombra en la ortoimagen resultante.

Sin embargo, el láser escáner se empleó en este trabajo para la documentación de una serie de elementos singulares del interior de la iglesia, como son los retablos, las cúpulas de madera y el frente del coro (Figura 25). Estos elementos poseen una geometría tridimensional muy compleja, de modo que su adecuada documentación mediante la fotografía rectificada no era posible, y con la estación total el tiempo de ejecución habría aumentado en exceso. Por ello, se optó por realizar un escaneo de estos elementos, que se llevó a cabo en un tiempo muy reducido, y se integraron las nubes de puntos de alta densidad parciales en el sistema de referencia global gracias al apoyo topográfico. Así se pudo elaborar una planimetría completa, optimizando los recursos mediante una adecuada combinación de técnicas.

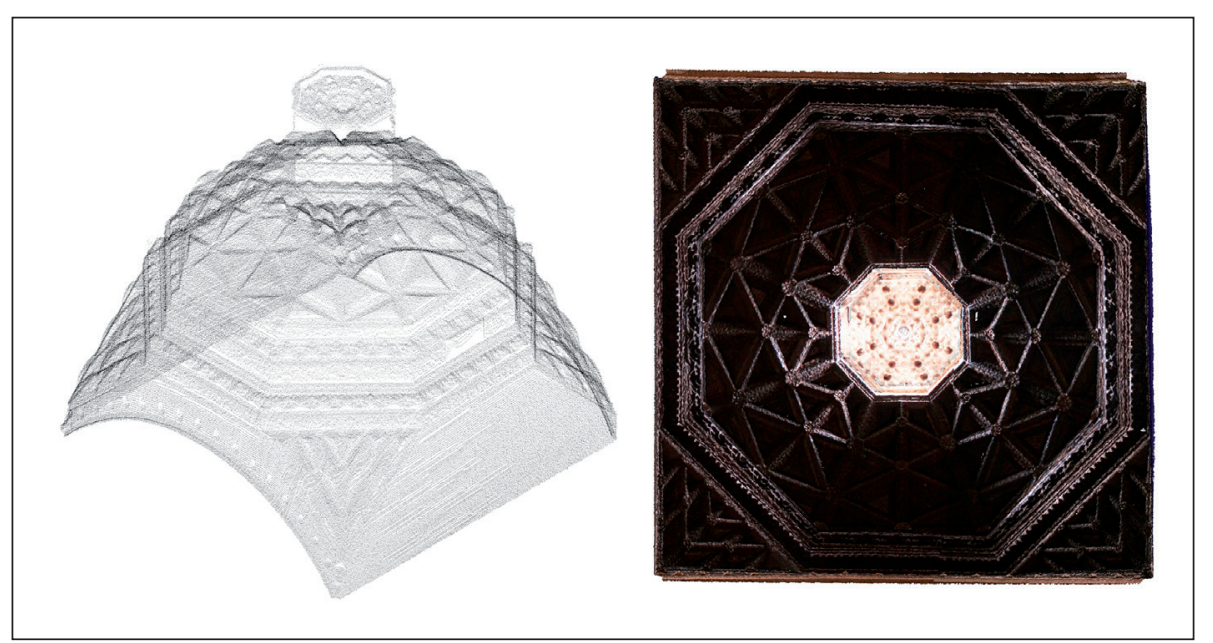

Figura 25. Nube de puntos a la izquierda y ortoimagen a la derecha de la bóveda de madera escaneada en la iglesia de de Santa María (Alaejos). Realización, Miguel Ángel Alonso. 


\section{4.- Capilla de la Mejorada (Olmedo) y capilla del Corpus Christi de la Catedral de Burgos}

Finalmente, queremos señalar dos trabajos con un enfoque análogo, puesto que se trata de espacios de reducidas dimensiones en los que se requería un alto nivel de detalle en la representación gráfica. Del primero, correspondiente a la capilla de los Becerra-Zuazo del Real Monasterio de Nuestra Señora de la Mejorada,

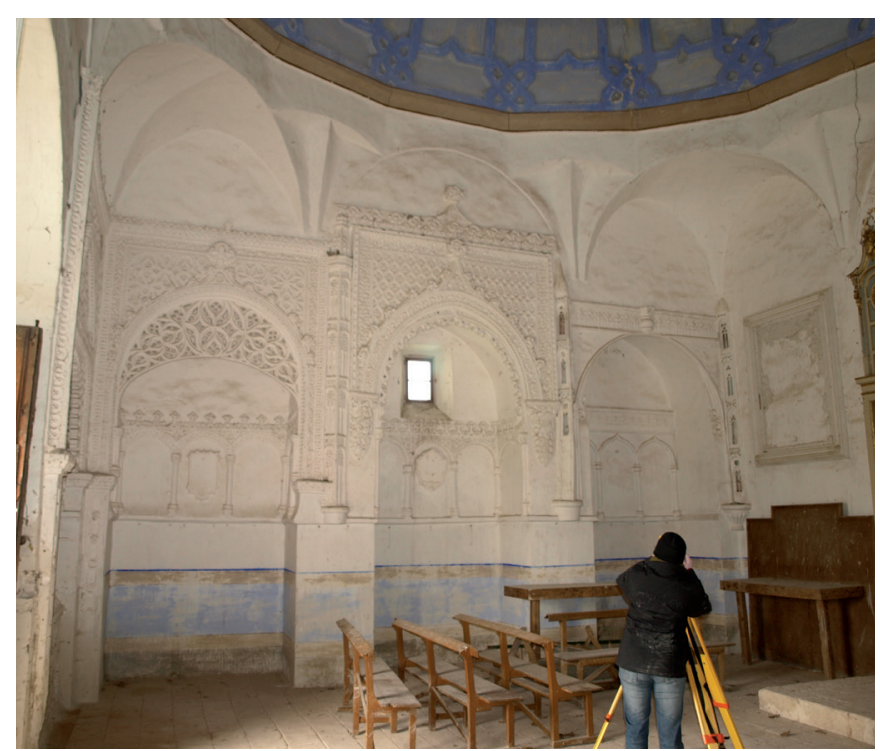

Figura 26. Vista interior de la capilla de la Mejorada (Olmedo). en Olmedo, queremos destacar el trabajo realizado en el interior, completamente revestido por enlucidos en sus paramentos, pero con una profusa decoración de yeserías sobre los mismos que había que documentar completamente (Figura 26). El segundo trabajo estaba dirigido a elaborar la planimetría completa del interior de la capilla del Corpus Christi de la catedral de Santa María en Burgos, una construcción íntegra en sillería que además posee motivos decorativos heráldicos en sus paramentos.

En ambos casos la documentación gráfica se planteó como base tanto para el análisis del edificio como para los proyectos de intervención que se iban a realizar. Puesto que se requería la delineación de todos los elementos, despieces y motivos decorativos, era precisa la obtención bien de un modelo tridimensional completo (a partir de fotogrametría estereoscópica), u ortoimágenes de cada uno de los alzados interiores (Figura 27). Dada la práctica ausencia de elementos intermedios que estorbasen las mediciones y la sencillez espacial de los recintos, hubiera sido un caso donde el empleo de escáner láser hubiese sido útil para generar ortoimágenes sobre las que delinear, ahorrando tiempo de ejecución en campo. Sin embargo, se optó por el empleo combinado de estación total con fotografía rectificada para reducir costes totales del trabajo y aprovechar el mayor tiempo en campo para analizar y entender el edificio que se iba a representar (Figura 28).

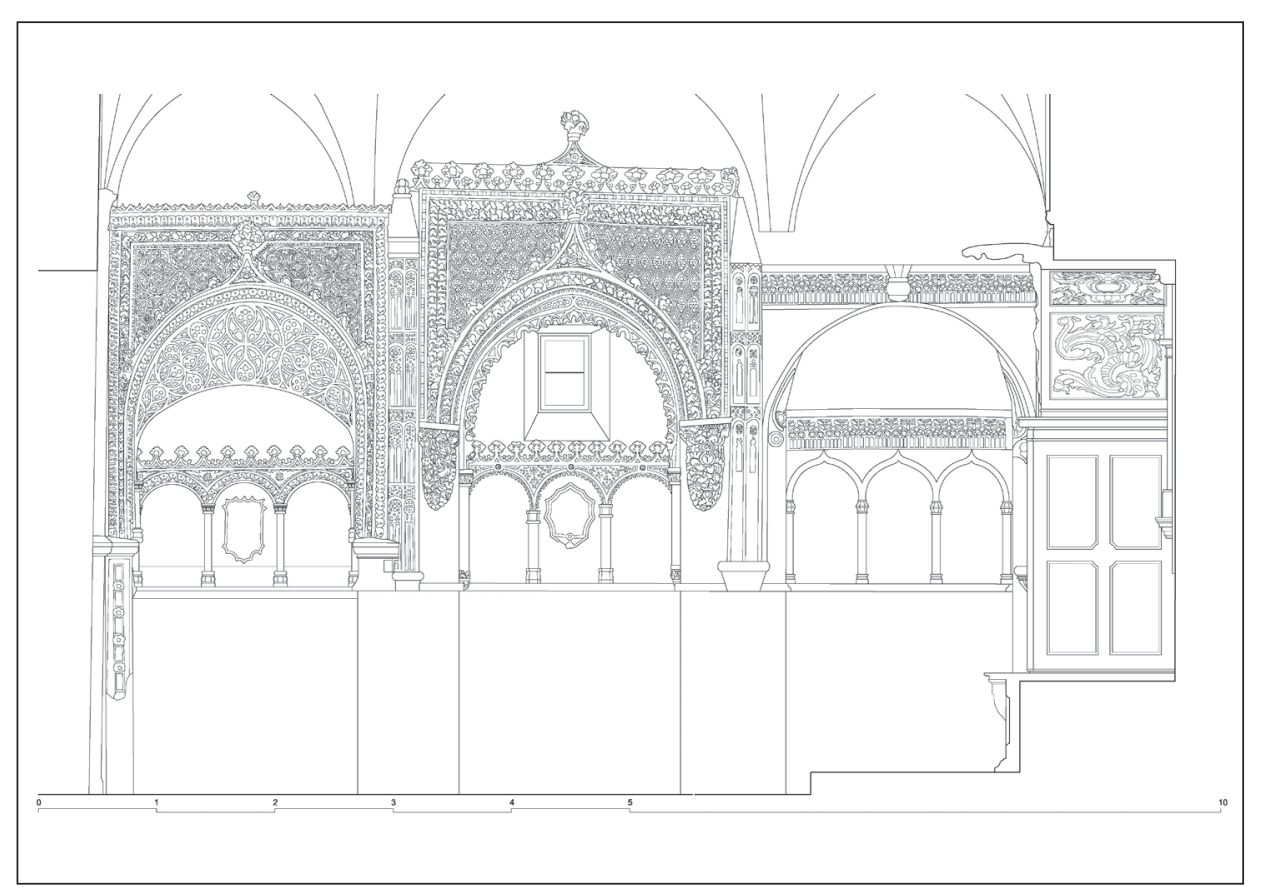

Figura 27. Detalle de la decoración de la capilla de la Mejorada (Olmedo). Realización, Carmen Pérez de los Ríos y Francisco Martínez González. 


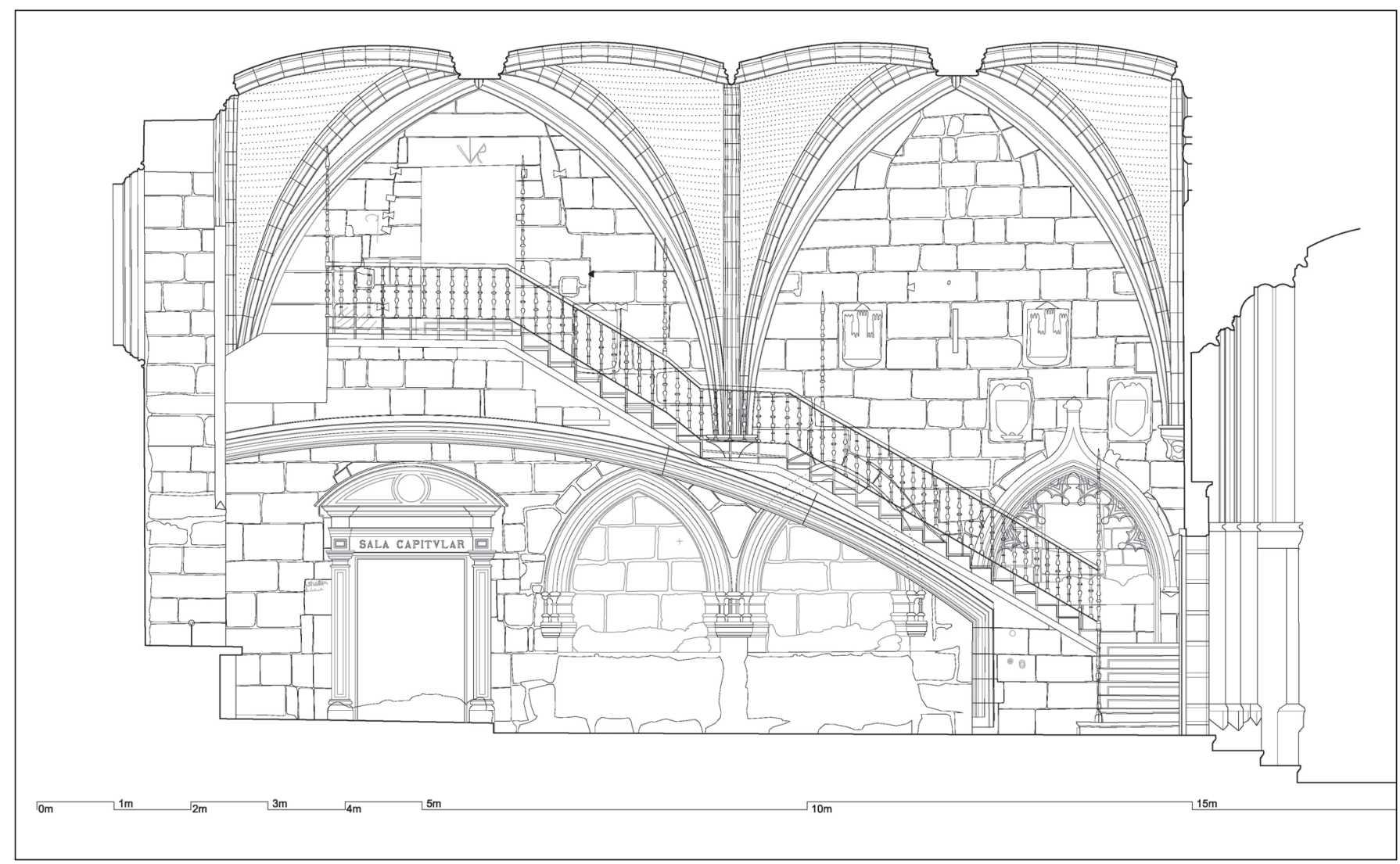

Figura 28. Sección de la capilla del Corpus Christi de la catedral de Santa María (Burgos).

\section{5.- CONCLUSIONES}

Las técnicas de documentación gráfica de edificios históricos han evolucionado rápidamente, apareciendo nuevos dispositivos, métodos y aplicaciones. Sin embargo, este desarrollo puede conducir a una cierta desorientación a la hora de la toma de decisiones por parte de los usuarios, que no deben quedar condicionados por las casas comerciales o profesionales interesados por una determinada técnica. Para ello, queremos destacar como conclusión a este artículo las ideas fundamentales que en nuestra opinión deberían tenerse en cuenta.

La primera de ellas radica en la importancia de entender la finalidad y los objetivos de la representación gráfica, siendo un paso previo a cualquier toma de decisiones. En este sentido, creemos que debe ser ante todo un medio para el conocimiento, la documentación y salvaguarda del patrimonio cultural y sus valores materiales. Así, el adecuado registro de los mismos supone automáticamente su preservación, incluso en casos extremos de pérdida del propio bien cultural. Por lo tanto, el primer paso en la selección de las técnicas debería ser el análisis del valor intrínseco del edificio a documentar.

Además de esta finalidad principal, es importante considerar las necesidades de los estudios y trabajos posteriores que tienen como base la documentación gráfica, los cuales definirán el tipo de resultado. En especial creemos que es de suma importancia asegurar la compatibilidad de la información en distintos soportes. En un mundo cada vez más interconectado, las posibilidades de uso de la documentación gráfica se multiplican, siempre y cuando se asegure la compatibilidad de la información. Y nos referimos a la compatibilidad no sólo pensando en términos estrictamente informáticos (formatos, aplicaciones, etc.), sino también a la posibilidad de que la documentación gráfica sea manejada por distintas personas, independientemente de su autor, por lo que debería ser editable, actualizable y contrastable. Esto es algo que desgraciadamente no ocurre en muchos casos, en los que el manejo de la información gráfica en su totalidad es casi imposible por parte de personas ajenas a su realización. 
En este sentido, la compatibilidad de la documentación depende en gran medida del método y los datos obtenidos. Una nube de puntos es un material en bruto que sólo puede ser manipulado generalmente por el autor de la toma de datos, ya que sin unas adecuadas referencias del objeto real se dificulta en gran medida su empleo por otras personas; sin embargo, un modelo tridimensional o una ortoimagen facilitan la comprensión del mismo. Para asegurar la compatibilidad, al igual que en un experimento científico, el proceso de la elaboración de la cartografía de un edificio debería describir exhaustivamente la metodología empleada, las hipótesis y variables asumidas, así como el grado de error máximo que se ha obtenido, e incluso deberían diferenciarse zonas, si las hubiese, con distinto nivel de rigor métrico. Aunque esto pueda entorpecer y ralentizar el proceso, entendemos que este aspecto es fundamental, ya que como hemos señalado al principio de este artículo, la documentación gráfica es en sí misma un proceso de investigación del edificio, y como tal deberían adoptarse estas pautas propias del método científico. Desafortunadamente no es ésta una práctica mayoritariamente generalizada, ni por iniciativa del autor del trabajo ni por exigencias del cliente.

Por otro lado, no creemos que exista una técnica «universal» cuya aplicación sea la más eficaz en todos los casos. Por ello, más allá de las recomendaciones de los proveedores de cada uno de los instrumentos o aplicaciones informáticas, entendemos que la auténtica habilidad del autor del levantamiento radica en la adecuada combinación de métodos, optimizando los recursos disponibles para conseguir los objetivos iniciales. En este sentido, la magnitud y alcance del levantamiento es un factor clave, puesto que es radicalmente distinto abordar la documentación gráfica de un elemento aislado (como por ejemplo una portada), las fachadas exteriores de un edificio, o también todos los espacios interiores, incluidos los más recónditos. Creemos de todos modos que el levantamiento no debería restringirse a las zonas afectadas por un determinado estudio o intervención, sino que, en la medida de lo posible, deberían abordarse trabajos integrales, que más allá de su función como herramienta de trabajo, sirvan al fin inicial de documentación y salvaguarda de los bienes culturales. Además, la documentación gráfica debería actualizarse con los cambios que se producen en el edificio (por ejemplo, fruto de las intervenciones restauradoras), para lo cual, una vez más, es imprescindible asegurar la compatibilidad de la información.
En cualquier caso, sean cuales sean las técnicas utilizadas o el alcance del trabajo, creemos que el resultado final, por su versatilidad, facilidad de manejo y compatibilidad, debería ser siempre la planimetría dibujada y adecuadamente referenciada a un único sistema de coordenadas. Además, como ya se ha mencionado, el proceso de dibujo supone un análisis, investigación e interpretación del objeto que añade un elevado valor al documento, sin que se pierda información dado que se conservan los datos en bruto. Frente a las opiniones que abogan por una sustitución del dibujo por otros medios de visualización, seguimos firmemente convencidos de la necesidad del mismo por su irreemplazable valor documental, así como por ser a día de hoy la herramienta más eficaz y compatible para todos los usuarios potenciales. En definitiva, entendemos que la planimetría dibujada, convenientemente complementada con los modelos tridimensionales y las ortoimágenes, constituye el producto más adecuado y potente para alcanzar los objetivos fundamentales de la documentación gráfica de los edificios históricos.

\section{Perspectivas de futuro}

No queremos terminar este artículo sin apuntar las que creemos que pueden ser líneas de innovación y desarrollo del campo de la documentación gráfica de edificios. En primer lugar, existe un terreno aún por investigar en el ámbito de la interpretación de los datos obtenidos automáticamente, especialmente las nubes de puntos de alta densidad. Como hemos comentado, esta información es totalmente indiscriminada, de modo que actualmente los procesos de selección de los datos relevantes son largos y complejos, lastrando la eficacia de las técnicas como el escáner láser o la fotogrametría convergente. Creemos que la obtención de procesos semiautomáticos para alcanzar dicha selección sería de gran ayuda. Por ejemplo, sería útil discriminar todos los puntos que pertenecen aproximadamente a un plano, sustituyéndolos por las líneas que definen su perímetro y hallando las intersecciones de planos adyacentes. De este modo, se conseguiría por un lado eliminar información inútil y, por otro lado, se obtendrían las líneas geométricas principales que definen los elementos. También cabría la posibilidad (y de hecho se han desarrollado algunos proyectos en este sentido) de vectorizar las ortoimágenes, para automatizar en la medida de lo posible la delineación de las mismas.

Además de la interpretación de los datos, se abre el campo de la gestión avanzada de los mismos mediante 
el empleo de sistemas SIG en modelos tridimensionales. La aplicación de estos sistemas sobre modelos de edificios históricos ya se viene llevando a cabo, aunque de un modo parcial y limitado, pero sin duda alguna estas experiencias apuntan una línea de investigación que en nuestra opinión puede ser de gran utilidad (Angulo 2012; Trizio 2009; Azkarate, Cámara, Lasagabaster y Latorre 1999). Queda ahora la puerta abierta a desarrollar herramientas que de un modo generalizado, accesible y compatible con múltiples usuarios permitan la vinculación de datos tanto históricos, como constructivos, patológicos, artísticos o sobre el uso del edificio, con su ubicación exacta en el mismo mediante modelos tridimensionales. En este sentido, el desarrollo de los modelos BIM (Building Information Modeling) aplicados a edificios históricos puede suponer también un avance en la gestión de la información. Tanto este tipo de modelos como los sistemas SIG amplían enormemente el alcance tradicional de la documentación de los edificios, superando el carácter gráfico para convertirse en potentes sistemas de información integrada. La posibilidad añadida de actualizar dicha información, hacer búsquedas selectivas y facilitar la accesibilidad de los datos permitiría generar potentes aplicaciones enfocadas a la investigación, la conservación, la gestión y la difusión del patrimonio cultural edificado.

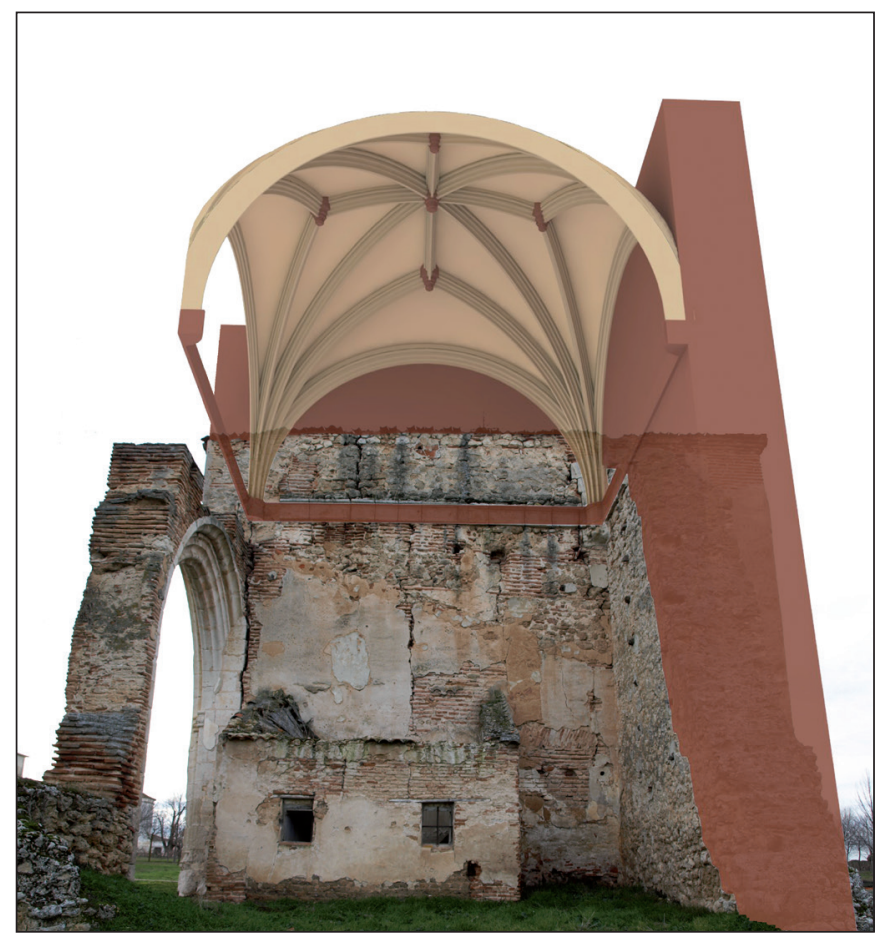

Figura 29. Reconstrucción virtual de la bóveda junto a la capilla de la Mejorada (Olmedo).
Finalmente, la cadena de valor del patrimonio incluye la difusión de sus valores culturales y en este ámbito las nuevas tecnologías pueden apoyar en gran medida. En concreto, la aplicación de la realidad aumentada y los sistemas ubicuos en dispositivos móviles permite basarse en los modelos tridimensionales, convenientemente simplificados, para superponer información virtual de carácter didáctico sobre las imágenes reales obtenidas por las cámaras de dichos dispositivos (Figura 29). Así, esta tecnología permite la visualización conjunta del edificio real desde un punto de vista concreto y la información deseada (reconstrucciones virtuales, animaciones, significación de unas partes respecto de otras del edificio, etc.), favoreciendo el entendimiento y el disfrute del patrimonio cultural por parte del público no especializado.

\section{Ficha técnica}

- Iglesia de Nuestra Señora del Campanario (Almazán). Trabajo contratado por la Fundación Duques de Soria en el marco del Proyecto Cultural «Soria Románica».

- Colegiata de Santa María (Valpuesta). Trabajo contratado por el Arzobispado de Burgos con el apoyo de la Junta de Castilla y León.

- Iglesia de Santa María (Alaejos). Trabajo contratado por la Junta de Castilla y León.

- Capilla de los Becerra-Zuazo del Real Monasterio de Nuestra Señora de la Mejorada (Olmedo). Trabajo contratado por la Junta de Castilla y León.

- Capilla del Corpus Christi en la Catedral de Santa María (Burgos). Trabajo contratado por la Fundación del Patrimonio Histórico de Castilla y León.

Salvo en los casos donde se indica lo contrario, todas las imágenes aquí incluidas han sido realizadas por el autor del artículo.

\section{Agradecimientos}

Quiero agradecer la colaboración prestada para la elaboración de este artículo mediante el permiso para la inclusión de imágenes a la Dirección General de Patrimonio Cultural de la Junta de Castilla y León, a la Fundación Catedral Santa María de Vitoria-Gasteiz, así como a Leandro Cámara, Rocío Maira, Despoina Tsiafakis, Georgios-Alexis Ioannakis y Andreas Sidiropoulos.

Finalmente, también deseo mostrar mi más sincero agradecimiento al equipo de investigadores y profesionales junto a los que he realizado diversos trabajos y que me han apoyado y animado para elaborar el presente texto. 


\section{6.- BIBLIOGRAFÍA}

Almagro, A. 2004: Levantamiento arquitectónico. Universidad de Granada, Granada.

Álvarez, I., Lopetegui, A., Mesanza, A., Rodríguez, A., Valle, J.M. y Vicente, I. 2003: "Diferentes propuestas para la representación geométrica", Arqueología de la Arquitectura, 2, pp. 9-12.

Angulo, R. 2012: "Construcción de la base gráfica para un sistema de información y gestión del patrimonio arquitectónico: Casa de Hylas”, Arqueología de la Arquitectura, 9, pp. 11-25.

Antoñanzas, M.A., Iguácel, P., Lopetegui, A. y Valle, J.M. 2003: "El Sequeral (Calahorra, La Rioja). Investigación fotogramétrica y arqueología", Arqueología de la Arquitectura, 2, pp. 13-16.

Azkarate, A., Cámara, L., Lasagabaster, J.I., Latorre, P. 1999: Catedral de Santa María Vitoria-Gasteiz. Plan Director de Restauración (2 vols.). Diputación Foral de Álava, Vitoria-Gasteiz.

Banerjee, R. y Srivastava, P.K. 2013: "Reconstruction of contested landscape. Detecting land cover transformation hosting cultural heritage sites from Central India using remote sensing", Land use policy: The International Journal Covering All Aspects of Land Use, 34, pp. 193-203.

Caballero, L. y Latorre, P. 1995: "La importancia del análisis estratigráfico de las construcciones históricas en el debate sobre la restauración monumental", Informes de la Construcción, 46, 435, pp. 5-18.

Cámara, L. y Latorre, P. 2003: "El modelo analítico tridimensional obtenido por fotogrametría. Descomposición, manipulación y aplicaciones en el campo de la restauración arquitectónica", Arqueología de la Arquitectura, 2, pp. 87-96.

Capitel, A. 1998: Metamorfosis de monumentos y teorías de la restauración. Alianza, Madrid.

Ceschi, C. 1970: Teoria e storia del restauro. Mario Bulzoni Editore, Roma.

Cusidó, J.A. 1996: "Aplicaciones de la termografía infrarroja y la espectrorradiometría en el estudio del deterioro del patrimonio arquitectónico nacional", Informes de la Construcción, 48, 443, pp. 15-26.

Docci, M. y Maestri, D. 1994: Manuale di rilevamento architettonico e urbano. Laterza, Roma.

García, F. 2003: "La técnica geofísica de ground penetrating radar (georradar) aplicada al patrimonio", en J.M. Iglesias (coord.) Actas de los XIV Cursos Monográficos sobre el Patrimonio Histórico (Reinosa, julio-agosto 2003), pp. 175-196. Universidad de Cantabria, Reinosa.
García-Gómez, I., Fernández de Gorostiza, M. y Mesanza, A. 2011: "Láser escáner y nubes de puntos. Un horizonte aplicado al análisis arqueológico de edificios", Arqueología de la Arquitectura, 8, pp. 25-44.

González-Varas, I. 1999: Conservación de bienes culturales. Teoría, historia, principios y normas. Cátedra, Madrid.

Iglesias, J. M. (coord.) 2002: "Experiencias cartográficas y fotogramétricas aplicadas a la conservación del Patrimonio Histórico”, en J. M. Iglesias (ed.), Actas de los XII Cursos Monográficos sobre el Patrimonio Histórico (Reinosa, julio-agosto 2001), pp. 215-332. ISPRS, International Society for Photogrammetry and Remote Sensing, Reinosa.

Jiménez, A. y Pinto, F. 2003: Levantamiento y análisis de edificios. Tradición $y$ futuro. Universidad de Sevilla, Sevilla.

Jokiletho, J. 1999: A History of Architectural Conservation. Butterworth Heinemann, ICCROM, Oxford.

Lamberini, D. 2003: Teorie e storia del restauro architettonico. Polistampa, Florencia.

Lichti, D., Pfeifer, N. y Maas, H-G. (eds.) 2008: Theme issue: Terrestrial Laser Scanning, Journal of Photogrammetry and Remote Sensing, 63, 1.

Mañana-Borrazas, P., Rodríguez, A. y Blanco-Rotea, R. 2008: “Una experiencia en la aplicación del Láser Escáner 3D a los procesos de documentación y análisis del Patrimonio Construido: su aplicación a Santa Eulalia de Bóveda (Lugo) y San Fiz de Solovio (Santiago de Compostela)", Arqueología de la Arquitectura, 5, pp. 15-32.

Martínez Justicia, M. J. 2000: Historia y teoría de la conservación y restauración artística. Tecnos, Madrid.

Ortega, J., Martínez, A. y Muñoz, M. J. 2011: “El dibujo y las vidas de los edificios”, Revista Expresión Gráfica Arquitectónica, 18, pp. 50-63.

Sainz, J. 2005: El dibujo de arquitectura. Teoría e historia de un lenguaje gráfico. Reverté, Barcelona.

Trizio, I. 2009: "Indagini Stratigrafiche e Sistemi Informativi Architettonici: il GIS della chiesa di S. Maria in Valle Porclaneta", Arqueología de la Arquitectura, 6, pp. 93-113.

Zamora, S. A., Pocoví, A. y Pueyo, O. 2005: “Aplicación de la prospección por georradar (GPR) a la delimitación y caracterización de estructuras arqueológicas. Ejemplo de las ruinas del convento agustino de Fraga", Geogaceta, 38, pp. 131-134. 